\title{
An actin nucleation complex catalyzes filament formation at sites of exocytosis
}

Oliver Glomb, Yehui Wu, Lucia Rieger, Diana Rüthnick**, Medhanie Mulaw, and Nils Johnsson

Institute of Molecular Genetics and Cell Biology, Department of Biology, Ulm University, James-Franck-Ring N27, D-89081 Ulm, Germany

* Comprehensive Cancer Center Ulm, Institute of Experimental Cancer Research, Ulm University, James-Franck-Ring N27, D-89081 Ulm, Germany

${ }^{*}$ ZMBH, University of Heidelberg, Im Neuenheimer Feld 282, D-69120 Heidelberg, Germany

Contact: Nils Johnsson, Institute of Molecular Genetics and Cell Biology, Department of Biology, Ulm University, James-Franck-Ring N27, D-89081 Ulm, Germany. Phone: + 4973150 36300. Fax: + 4973150 36302. E-mail: nils.johnsson@uni-ulm.de

Running title: Boi1/2 induce actin filaments

Key words: polar growth/vesicular traffic/actin nucleation/cdc42 


\section{Abstract}

Due to the local enrichment of factors that influence its formation, dynamics, and organization, the actin cytoskeleton displays different shapes and functions within the same cell. In yeast cells post-Golgi vesicles ride on long actin cables to the bud tip. The scaffold proteins Boi1 and Boi2 participate in tethering and docking these vesicles to the plasma membrane. Here we show that Boi1/2 also recruit nucleation and elongation factors to form actin filaments at sites of exocytosis. Disrupting the physical connection between Boi1/2 and the nucleation factor Bud6 impairs filament formation in the bud, reduces the directed movement of the vesicles to the tip, and shortens their tethering time at the cortex. Artificially transplanting Boil from the bud tip to the peroxisomal membrane partially redirects the actin cytoskeleton and the vesicular flow towards the peroxisome, and creates an alternative, rudimentary vesicle-docking zone. We conclude that Boi1/2 is sufficient to induce the formation of a cortical actin structure that receives and aligns incoming vesicles before fusing with the membrane. 


\section{Introduction}

The directed transport of post-Golgi vesicles influences the shape of cells and forms diverse structures such as axons in animals, hyphal extensions in fungi, or pollen tubes in plants. Polar growth is the result of a complex interplay between RhoGTPase-based signaling, cytoskeletal organization, vesicular traffic and fusion. By growing through budding, yeast serves as a model organism to understand the molecular mechanisms behind polar growth. The bud tip of yeast cells is the site of preferred exocytosis and hosts a complex assembly of proteins that tether the vesicle to the plasma membrane. Vesicles arrive at these sites on actin cables by a myosin type-V (Myo2) driven transport (Jin et al. 2011). Post-Golgi vesicles do not immediately fuse with the PM but stay immobile for a defined time at or close by the site of their prospective fusion. This dwell time depends among other factors on the vesicle-bound Myo2 and thus on the presence of an actin structure adjacent to the site of fusion (Donovan and Bretscher 2015; Lepore, Martinez-Nunez, Munson 2018).

Linear actin cables that point to the bud tip are formed by the nucleation-promoting factor Bud6 in cooperation with the formin Bni1 (Amberg et al. 1997; Graziano et al. 2011; Moseley et al. 2004). Bud6 and Bni1 co-localize to the tip of the bud as members of the polarisome multi-protein complex (Amberg et al. 1997; Sheu et al. 1998). Full activation of this complex requires the binding of small Rho-GTPases to relive the autoinhibition of Bni1 (Evangelista et al. 1997; Li, F. and Higgs 2003; Li, F. and Higgs 2005). Deletion of core components of the polarisome dissolve the focused distribution of Bud6 and Bni1, yet leave actin filament formation and the delivery of vesicles less tip-directed but otherwise still largely intact (Tcheperegine, Gao, Bi 2005). This finding suggests the existence of additional factors that position filament formation at the membrane of the bud. We describe a complex consisting of Bud6, Bni1 and the vesicle 
bioRxiv preprint doi: https://doi.org/10.1101/715409; this version posted July 25,2019 . The copyright holder for this preprint (which was not certified by peer review) is the author/funder, who has granted bioRxiv a license to display the preprint in perpetuity. It is made available under aCC-BY-ND 4.0 International license.

tethering factors Boi1 and Boi2 that initiates the formation of actin filaments at or close

to the sites of vesicle fusion. 


\section{Results}

\section{Boi1/2 physically interact with actin nucleation and elongation factors}

To identify alternative regulators of actin filament nucleation in the bud, we performed a systematic Split-Ubiquitin (Split-Ub) interaction analysis and screened Bni1 and Bud6 as $\mathrm{C}_{\mathrm{ub}}$-RUra3-fusions (CRU) against an array of $504 \mathrm{~N}_{\mathrm{ub}}$ fusion proteins (Hruby et al. 2011; Johnsson and Varshavsky 1994; Wittke et al. 1999). The Split-Ub analysis revealed among specific binding partners for Bni1 or Bud6, Boi1 and Boi2 as shared interaction partners of both proteins (Fig. 1A, Fig. S1, Table S1). Boi1 and Boi2 are homologous proteins that assist in the tethering and fusion of post-Golgi vesicles at the plasma membrane and thus qualify as candidates for organizing actin filaments in the bud (Kustermann et al. 2017; Masgrau et al. 2017). Both proteins were already shown to interact with Bud6 in vivo (Kustermann et al. 2017). As Boi1 and Boi2 perform their essential functions redundantly, we performed our molecular analysis predominantly on Boi1 (Kustermann et al. 2017). Split-Ub interaction analysis in strains lacking either BUD6 or BNI1 confirmed that both proteins interact independently of each other with Boi1 (Fig. 1B). $\mathrm{N}_{\mathrm{ub}}$ fusions to fragments of Boi1 or Boi2 localized the binding sites for Bud6 and Bni1 to their N-terminal 300 residues (Fig. 1C.) Split-Ub analysis of CRU fusions to fragments of Bni1 placed the binding site for Boi1 within the N-terminal 854 residues of Bni1 and thus away from the C-terminally located binding site for Bud6 (Fig. 1D). $N_{u b}$ fusions to fragments of Bud6 allowed confining the Boi1-interaction site to the N-terminal 141 residues of Bud6 (Fig. 1E). We expressed the so-defined minimal binding fragments of Boi1 (1-203), Bud6 (1-141), and Bni1 (1-854) in E.coli and could show by pull down analysis that the interaction between Boi1 and Bni1 and between Boi1 and Bud6 are direct (Fig. 1F). To obtain a mutation that disrupts the interaction to Bud6 without grossly disturbing the structure of Boi1, we further fine-mapped the Bud6 interaction site on Boi1. A screen of $\mathrm{N}_{\mathrm{ub}}$ fusions to different $\mathrm{N}$-terminal fragments of 
Boi1 identified the linker region (residues 77-178) between the SH3 and the SAM domain as autonomous binding site for Bud6 (Fig. S2). A pull-down of the purified Histagged Bud6 ${ }_{1-141}$ with a GST fusion to Boi ${ }_{77-178}$ confirmed our analysis (Fig. S2). We deleted the Boi1-linker region in the yeast genome $\left(\right.$ boi $\left._{\Delta 86-178}\right)$ and tested the Boi $1_{\Delta 86-}$ ${ }_{178} \mathrm{CRU}$-expressing strain against the $\mathrm{N}_{\mathrm{ub}}$ array. The analysis confirmed that $\mathrm{Boi}_{\Delta 86-178}$ had specifically lost its interaction to Bud6 (Fig. 1G). The interactions with other polarity proteins like Bem1 as well as Sec1 remained unaffected by this deletion (Figs. 1G, S2). The deletion did not detectably impair the interaction between Boi1 and Bni1 (Fig.1H). Overexpressing Boi1-mCherry leads to large un-budded cells whose plasma membrane is stained by Boi1-mCherry (Fig. 1J). Co-staining the actin structures in these cells with Lifeact, or co-staining with GFP fusions to Bud6 or Bni1 visualizes the relocation of all three proteins to the Boi1-mCherry-stained cortex, suggesting that Boi1 binds to the Bni1/Bud6 complex in its active actin filament-promoting conformation (Figs. 1I, J).

\section{The Boi proteins influence the actin cytoskeleton independently of their vesicle fusion activity.}

Boi1/2 might guide the Bud6/Bni1-complex to generate actin filaments at sites of exocytosis. We visualized the actin cytoskeleton in $\Delta$ boi $1 \Delta$ boi2 cells expressing fragments of Boi1 of increasing length. The C-terminal $\mathrm{PH}$ domain of Boi1 is the minimal fragment that rescues the essential function of Boi1/2 during vesicle fusion. Cells expressing this domain (boi $1_{\Delta 414} \Delta$ boi2) were significantly enriched in delocalized actin patches and contained fewer and thinner actin cables as the corresponding BOI1 $\triangle$ boi2-cells (Fig. 2A, B). This effect documents a clear impact of Boi1/2 on the actin cytoskeleton. We next correlated the presence of the Bud6/Bni1 binding sites on the expressed Boi1-fragments with changes of the actin cytoskeleton in these cells. A 
deletion of the first 203 residues removes the major Bud6 binding site of Boi1 and affects the binding to Bni1. This deletion already reduced the percentage of actin cables and also increased the amount of de-localized actin patches. Additionally removing the SAM domain of Boi1 (boi1 $\left.1_{\triangle 299}\right)$ and thus any residual interactions with the Bud6-Bni1 complex further lowered the amount of actin cables and enhanced the number of delocalized actin patches to similar levels as found in cells expressing only $B o i 1_{\Delta 414}$. The impaired vesicle fusion of a $\Delta$ boi1 $\Delta$ boi2 strain can be suppressed by overexpression of the t-SNARE Sso1 (Kustermann et al. 2017). The still disorganized actin structure of this strain confirms that actin organization and vesicle docking are distinct activities of Boi1/2 (Fig. 2B). A GFP fusion to the Rab-GTPase Sec4 is a marker for post-Golgi vesicles, which become highly polarized in the growing bud (Jin et al. 2011). Truncating Boi1 from its $\mathrm{N}$-terminus increasingly dissolved the tip-focused distribution of these vesicles (Fig. 2A, C). This observation further substantiates the role of Boi $1 / 2$ in actin organization as secretory vesicles strictly travel on actin cables (Pruyne, Schott, Bretscher 1998).

\section{The Boi1-Bud6 complex stimulates actin filament formation in the bud}

The high density of actin patches interferes with the simultaneous detection of actin cables in the bud. We thus repeated the actin staining of $\Delta$ boi2-cells carrying the minimally perturbed boi $_{\Delta 86-178}$ allele after treatment with the actin patch inhibitor CK666 (Hetrick et al. 2013). Structured illumination microscopy (SIM) of the actin cytoskeleton showed that the bud of boi $1_{\Delta 86-178} \Delta$ boi2 cells was less densely filled with actin filaments than BOl1 $\triangle$ boi2 cells (Fig. 2D). Applying the coefficient of variation as quantitative measure we could support the conclusion derived from the visual analysis of the cells (Fig. 2E) (Garabedian et al. 2018)(see Materials and Methods). Compared to wild type BOI1BOI2- and BOI1 $\triangle$ boi2-cells, boi $1_{\triangle 86-178} \triangle$ boi2-cells also displayed 
fewer actin filaments crossing a virtual plane that was placed in the bud perpendicular to the polarity axis (Fig. 2E). In contrast, actin filament number and density were not changed in mother cells upon deletion of the Bud6 binding site in Boi1 (Fig. 2E, F). The polar localization of Bud6 was not affected in boi1 ${ }_{\Delta 86-178} \Delta$ boi2-cells (Fig. S3).

\section{Cortical actin modulates vesicular flow and fusion}

To measure the influence of the Boi1/2 induced actin structures on the movement and fusion of post-Golgi vesicles, we photo-bleached the buds of cells expressing GFPSec4 and compared the trajectories of individual vesicles entering the bud of $\mathrm{BO} 11$ BOI2-, BOl1 $\triangle$ boi2- and boi1 ${ }_{\Delta 86-178} \Delta$ boi2-cells by time-lapse microscopy (Video_S1) (Donovan and Bretscher 2015). Incoming vesicles in wild type cells were often directly transported to the cell cortex, where they either tethered and subsequently fused, or moved along the cortex to the tip where fusion occurred. Incoming vesicles in $\Delta$ boi2and more pronounced in boi $1_{\Delta 86-178} \Delta$ boi2-cells took longer to find their final destination (Video_S1). Especially post-Golgi vesicles in boi $1_{\Delta 86-178} \Delta$ boi2-cells headed after their first contact with the cortex to a different region of the cortex or tumbled in the center of the bud. We occasionally observed an incoming vesicle that was redirected into the mother cell after shortly touching the cortex of the bud. Moreover, incoming vesicles seemed to reside longer at the neck before entering the bud (Video_S1).

To quantify the differences between the alleles, we measured the GFP-Sec4 fluorescence intensity of a small corridor adjacent to the PM of the bud and normalized it to the intensity of the whole bud (Fig. 3A). In wild type cells, GFP-Sec4 staining was clearly restricted to the narrow zone beneath the plasma membrane. In boi1 $\Delta 86-178$ $\triangle$ boi2-cells GFP-Sec4 was more equally distributed throughout the bud. GFP-Sec4 was also slightly enriched at the bud neck of these cells (Fig. 3A). 
Tracking individual post-Golgi vesicles is best achieved in medium-sized and large buds. To complement our tracking experiments, we observed GFP-Sec4 by SIM of fixed cells to look at the distribution of post-Golgi vesicles in small buds where vesicular traffic is more tip-directed. Vesicles stained the cortex in a very restricted zone at the tip of wild type cells (Fig. 3B). This zone became slightly broader in BOI1 $\triangle$ boi2-cells (Fig. 3B). This trend continued in boi $1_{\Delta 86-178} \Delta$ boi2-cells where the GFP-Sec4-staining also extended more toward the center of the bud and additionally appeared as small cluster at the bud neck (Fig. 3B).

Vesicles that reached their final destination at the cortex stayed there in average for 10.85 s before disappearing, most probably through fusion with the plasma membrane. The tethering time was significantly reduced to $7.7 \mathrm{~s}$ in boi $1_{\Delta 86-178} \Delta$ boi2-cells. As $\Delta$ boi2-cells displayed a near wild type tethering time of $10.5 \mathrm{~s}$, we conclude that a loss of the Bud6-interaction site in boi1 ${ }_{\Delta 86-178}$ causes a faster fusion of vesicles with the plasma membrane (Fig. 3C).

\section{Boi1/2 form autonomous actin nucleation sites}

The Boi1/2-independent location of Bud6, as well as the prominent presence of heterogeneous, Boi1/2-independent actin structures in the bud prevents the straightforward conclusion that Boi1/2 initiate actin filaments de novo (Fig. S3). By fusing Boi1 to Pex3, a membrane protein of the peroxisomes, we removed Boi1 from the known actin nucleation centers of the bud to study its activity in isolation at the membrane of the peroxisome (Fig. 4A) (Luo, Zhang, Guo 2014). Pex3 ${ }_{1-45}$ mCherry-Boi1 (Pex-Boi1) is efficiently targeted to the membrane of the peroxisomes (Fig. 4B). By coexpressing a GFP fusion to proteins involved in polar growth including known ligands of Boi1/2, we could show that Boi1 attracts all its tested binding partners to the peroxisome including members of the exocyst (Fig. 4C, 4E, S4). 
Actin staining revealed the establishment of an alternative axis of cell polarity in the Pex-Boi1-expressing cells (Figs. 4 C, D). The actin cables of this alternative axis seem to emanate from peroxisomes located in the mother. To distinguish the contribution of the actin nucleation factors from the contributions of all other recruited proteins, we repeated the experiments with cells expressing peroxisome-targeted Boi $1_{\Delta 86-178}$ (PexBoi $1_{\triangle 86-178}$ ) lacking the binding site to Bud6. Accordingly, Bud6-GFP was not longer found at Pex-Boi1 ${ }_{\Delta 86-178}$-labelled peroxisomes, whereas Bni1, the exocyst subunit Exo84 as well as other members of the polarity complex still co-localized (Figs. 4C, S4, Table S2). Actin cables in this strain were often less polarized towards the cell tip but did not any longer align towards the peroxisomes (Fig. 4C, D). A significant portion of cells still contained actin patches around peroxisomes (Fig. 4D).

The GFP fusion of the v-SNARE Snc1 (GFP-Snc1) and Sec4 were also enriched at the peroxisomes of Pex-Boi1- but not of Pex-Boi $1_{\Delta 86-178}$ expressing cells (Fig. $5 A, B$ ). As both GFP-fusions are attached to post-Golgi vesicles, their recruitment to the peroxisome indicates the reconstitution of an at least partially functional vesicletethering zone. Consequently, Boi1- but not Boi $1_{\Delta 86-178}$-labelled peroxisomes, when found in close apposition to the PM, often induce an outward bulging of the cell wall (Figs. 4C, 5A).

Tracking of individual GFP-Sec4-labeled post-Golgi vesicles confirmed the formation of an alternative and functional polarity axis (Video_S2) (Fig. 5C, D). Cells containing Boi1-decorated peroxisomes displayed a reduced flux of vesicles to the bud (Fig. 5C, D). The reduction was accompanied by an increase in the fraction of vesicles that moved away from the bud towards the Boi1-labed peroxisomes (Fig. 5C, D). This redirection of vesicular traffic was not seen in cells expressing Pex-Boi $1_{\Delta 86-178}$ (Fig. 5 C, D). The measured directional vesicular traffic was strictly actin-dependent (Fig. 5E). 


\section{Discussion}

In most eukaryotic organisms post-Golgi vesicles arrive at the cell plasma membrane through a directed long-distance walk on microtubules or actin cables. The vesicles are then handed over to the actin filaments underlying the cortex (Hume et al. 2011; PoratShliom et al. 2013). The actin-bound vesicles are either kept on hold during regulated exocytosis or processed directly for docking and fusion. In budding yeast post-Golgi vesicles are transported exclusively on actin cables to the plasma membrane of the bud (Pruyne, Schott, Bretscher 1998). We propose that in budding yeast, similar to other eukaryotes, secretory vesicles switch from actin cables used for long-distance transport to cortical actin filaments that guide the vesicle to the docking and fusion zone. Our experiments point to Boi1/2 as nucleation sites for actin filaments below the plasma membrane. Boi1/2 locate at the cortex and bind to Bud6 and the formin Bni1, two proteins that form a potent actin nucleation and elongation complex (Graziano et al. 2011; Graziano et al. 2013; Moseley and Goode 2005). Abrogating the interaction between Boi1/2 and Bud6 reduces actin cable density in buds, increase the random movement of vesicles, and shortens the tethering time of the bound vesicles. Furthermore, the artificial relocation of Boi1 to peroxisomes creates an alternative tethering zone at the peroxisome including secretory vesicles and actin filaments that emanate from these sites. The zone is formed by the many binding partners of Boi 1 and depends on Boi1's ability to recruit Bud6 to initiate actin cables (Fig. 6). The efficacy by which the peroxisome-tethered Boi1 competes with other factors in the cell for actin filament formation might suggest that Boi1/2 not only anchors but also activates the Bud6/Bni1 complex upon binding.

By focusing our analysis on the boi $1_{\Delta 86-178}$-allele, we tried to separate its influence on actin filament formation from the protein`s two other main functions, the localization of the Bem1-Cdc24 complex and the formation of the tethering and docking complex 
(Bender et al. 1996; Kustermann et al. 2017). The former activity is located on a short binding motif in the middle of the sequence of Boi1, whereas the latter activity locates on the membrane- and Sec1-binding C-terminal PH domain, and the Exo84-, Sec3binding N-terminal SH3 domain (Bender et al. 1996; Kustermann et al. 2017). We propose that the concentration of all three activities in one protein coordinates vesicle fusion with trafficking and enables the control of both activities through Rho-GTPases (Fig. 6A). Linking vesicle tethering/fusion with actin nucleation might foster vesicle docking at sites where fusion has recently occurred and thus equip secretion with the processivity that is required for polarized growth (Fig. 6B). Binding to Bem1-Cdc24

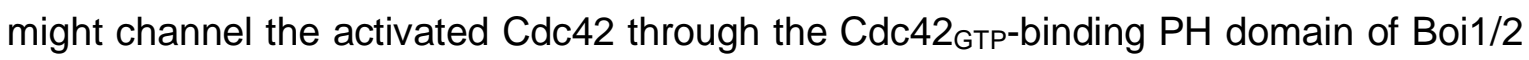
directly to Bni1, and the exocyst components Sec3 and Exo70 that tether the vesicle to the membrane and together with the other exocyst components catalyze the formation of the docking complex (Fig. 6A) (Adamo et al. 2001; Guo et al. 1999; Guo, Tamanoi, Novick 2001; He et al. 2007; Morgera et al. 2012; Yue et al. 2017).

The reduction in vesicle tethering time through the dissolution of the Boi1-Bud6 complex seems counterintuitive, yet might indicate that the cortical actin in yeast as in higher eukaryotes not only directs movement to the membrane but also restricts and controls the access of the vesicles to the plasma membrane (Li, P. et al. 2018; Meunier and Gutierrez 2016). This conclusion is supported by the phenotype of cells carrying a bud6 deletion. Here the number of actin cables is reduced, but the velocity of postGolgi vesicles, and the randomness of their movements is increased. At the same time exocytosis became less efficient in these cells (Jose et al. 2015).

Although budding yeast uses only actin structures for transport and docking, the significance of our findings is not restricted to these cells. Studies in neuroendocrine cells showed that the role of the cortical actin cytoskeleton is quite similar with respect to the coordination of exocytosis, where it also directs vesicular flow, and mediates 
docking and fusion (Chasserot-Golaz et al. 2005; Gabel et al. 2015; Gonzalez-Jamett et al. 2017; Maucort et al. 2014). Upon stimulation, actin associated proteins like the actin bundling protein AnnexinA2 are targeted to the SNARE complex at the plasma membrane to reorganize the integrity of the cortical actin cytoskeleton and generate a vesicle fusion-promoting environment (Gabel et al. 2015; Umbrecht-Jenck et al. 2010). The fission yeast S.pombe transports post-Golgi vesicles on microtubules. Deletion of its single Boi homologue Pop1 leads to the accumulation of secretory vesicles in the cytosol (Nakano et al. 2011). Pop1 was also shown to bind to the S.Pombe formin For1. Disrupting this interaction disturbs the actin cytoskeleton (Rincon et al. 2009). Pop1 complements the essential function of Boi1/2 in vesicle fusion (Kustermann et al. 2017). These findings indicate that the molecules and mechanisms involved in the transfer of secretory vesicles from their long-distance carrier to cortical actin structures are quite conserved. 


\section{Materials and Methods}

\section{Growth conditions and cultivation of strains}

All yeast strains in this study are derivatives of the Saccharomyces cerevisiae JD47 strain. Cells were incubated at $30^{\circ} \mathrm{C}$ in YPD or synthetic medium lacking specific amino acids or complemented with antibiotics for selection. E.coli XL1 blue cells were used for plasmid amplification and grown at $37^{\circ} \mathrm{C}$ in LB medium containing antibiotics. E.coli BL21 cells were used for protein production and were grown in LB or SB medium at $37^{\circ} \mathrm{C}$ or $18^{\circ} \mathrm{C}$.

\section{Construction of plasmids and strains}

Detailed lists of all primers and plasmids from this study are provided in Tables S3 and S4. Fusions of GFP or CRU to $B U D 6, B N I 1, B O I 1$ or boi1 $1_{\Delta 86-178}$ were constructed by PCR amplification from genomic DNA of the respective C-terminal ORFs without stop codon as described (Dunkler, Muller, Johnsson 2012; Fujimura-Kamada, Hirai, Tanaka 2012; Kustermann et al. 2017; Manavalan and Johnson 1987; Norden et al. 2006; Wittke et al. 1999). The obtained DNA fragments were cloned via Eagl and Sall restriction sites in front of the CRU-, GFP-, mCherry- module on a pRS303, pRS304 or pRS306 vector (Sikorski and Hieter 1989). For integration into the genome, the plasmids were linearized using a single restriction site within the C-terminal genomic DNA sequence. Successful integration was verified by PCR of single yeast colonies with diagnostic primer combinations using a forward primer annealing in the target ORF but upstream of the linearization site, and a reverse primer annealing in the C-terminal module. Gene deletions were obtained by replacing the ORF with an antibiotic resistance cassette through single step homologous recombination as described (Janke et al. 2004). Genomic $N_{u b}$ fusions were obtained as described (Hruby et al. 2011). Generation of yeast centromeric plasmids containing $\mathrm{N}_{\mathrm{ub}}$ fusion proteins included initial PCR amplification of indicated fragments from genomic DNA containing 
a Sall restriction site in the forward- and Acc65I restriction site in the reverse primer and ligated into the plasmid $N_{u b}$-empty kanMX4.

Fragments of BUD6, BNI1 or BOI1 were expressed as GST- or 6xHis- fusions in E.coli

BL21. GST-fusions were obtained by amplification of the respective fragments from genomic yeast DNA using primers containing Ncol/EcoRI restriction sites. The PCR fragments were cloned in-frame behind GST in the plasmid pGex6P1 or pGex2T (GE Healthcare, Buckinghamshire, UK). For 6xHis-tagged fragments, a PCR of the respective fragment from genomic DNA using primers containing Sfil restriction sites was performed and the product was inserted in frame downstream of a 6xHis-tag into the pAC plasmid (Schneider et al. 2013). The chimeric Pex3 ${ }_{1-45}$ mCherry pRS306 plasmid was adapted from Luo et al. (Luo, Zhang, Guo 2014). BOI1 or boi1 ${ }_{\Delta 86-178}$ were amplified from genomic DNA and inserted in frame behind the mCherry tag using BamHI/Sall restriction sites.

Genomic integration of the boi1 ${ }_{\Delta 86-178}$ allele was performed by „delitto perfetto“ methodology or CRISPR CAS9 (Laughery et al. 2015; Storici and Resnick 2006). The successful deletion/exchange of amino acids were confirmed by sequencing of singlecolony PCRs. A detailed description of the construction of all plasmids can be obtained upon request.

\section{In vitro binding assays}

\section{Protein expression}

O.n. cultures of E.coli BL21 cells were diluted to $\mathrm{OD}_{600}=0.3$, and incubated at $37^{\circ} \mathrm{C}$ in LB or SB medium to an $\mathrm{OD}_{600}=0.8$ before protein synthesis was induced by the addition of IPTG. Protein expression conditions were optimized for each expression construct (see Table S5). Cell pellets were stored after induction at $-80^{\circ} \mathrm{C}$. 
Cell pellets were resuspended in $1 x$ PBS or 1x HBSEP $(\mathrm{pH} 7.4,10 \mathrm{mM}$ Hepes, $150 \mathrm{mM} \mathrm{NaCl}, 3 \mathrm{mM}$ EDTA, 0.005\% Tween-20) containing 1x protease inhibitor cocktail (Roche Diagnostics, Penzberg, Germany), incubated for 20 min with $1 \mathrm{mg} / \mathrm{ml}$ lysozyme on ice, and subsequently subjected to sonification for $2 \times 4$ min with a Bandelin Sonapuls HD 2070 (Reichmann Industrieservice, Hagen, Germany). Lysates were spun down at $40.000 \mathrm{~g}$ for $10 \mathrm{~min} / 4^{\circ} \mathrm{C}$. Supernatants were transferred either directly to the binding assay, or used for further purification.

\section{Binding assay}

All incubation steps were carried out under rotation in the cold room. Extracts of GST or GST-fusion proteins were incubated for $0.5-1 \mathrm{~h}$ with glutathione-coated sepharose beads (GE Healthcare, Freiburg, Germany) equilibrated in PBS (Boi1-Bni1) or HBSEP (Boi1-Bud6). Beads were washed twice and incubated with $0.1 \mathrm{mg} / \mathrm{ml} \mathrm{BSA}$ (Boi1-Bni1) (Sigma Chemicals, St.Louis, USA) for 30 min before the beads were treated with either purified $2 \mu \mathrm{M} 6 \mathrm{xHis}$ Bud6 $_{1-141}$, or extract of $6 \mathrm{xHis}$ Boi1 $1_{1-300}$ in the presence of $0.1 \mathrm{mg} / \mathrm{ml}$ BSA for 1h. Beads were washed $3 \times$ with HBSEP or PBS before eluting the bound protein with 1xGST elution buffer ( $\mathrm{pH} 8.0,50 \mathrm{mM}$ Tris, $20 \mathrm{mM}$ reduced glutathione).

Protein eluates were separated by SDS PAGE and stained with Coomassie Brilliant Blue or with anti-His antibody after transfer onto a nitrocellulose membrane (SigmaAldrich, Steinheim, Germany; dilution 1: 5000).

\section{Quantification of Western blots}

Western blots were quantified with ImageJ. A detailed step-by-step procedure is given in (University of Queensland, Diamantina Institute, 27 April 2017, https://di.uq.edu.au/community-and-alumni/sparq-ed/sparq-ed-services/using-imagejquantify-blots). Briefly, the histogram of the intensities of each band of a western blot was used to calculate the area under the curve (AUC), which correlates to the size and brightness of each band. The AUC of each band was normalized to the AUC of the 
input band to quantitatively compare the amount of bound 6xHis-tagged fusion protein in each lane of the gel.

\section{Protein purification}

For purification of $6 \mathrm{xHis}-\mathrm{Bud} 66_{1-141}$ cell pellets were extracted as above in $1 \mathrm{x}$ IMAC binding buffer ( $\mathrm{pH}$ 7.5, $300 \mathrm{mM} \mathrm{NaCl}, 50 \mathrm{mM} \mathrm{KH2PO4,} 20$ mM Imidazole). Purification was achieved by immobilized metal affinity purification followed by size exclusion chromatography (SEC) on an ÄktaPurifier Chromatography System (GE Healthcare, Buckinghamshire, UK).

The final protein concentration was determined with a NanoDrop ND-1000 spectral photometer (Peqlab, Erlangen, Germany) at $280 \mathrm{~nm}$ excitation, and based on a calculated excitation coefficient of $8.5 \mathrm{mM}^{-1} \mathrm{~cm}^{-1}$ and a molecular weight of $17.7 \mathrm{kDa}$ (www.expasy.org). The purified protein was used either directly for pull down analysis or stored at $-20^{\circ} \mathrm{C}$.

\section{In vivo interaction analysis with the Split-Ubiquitin system}

Split-Ubiquitin array analysis: A library of 533 different $\alpha$-strains each expressing a different $\mathrm{N}_{\mathrm{ub}}$ fusion were mated with a Bni1CRU-, Bud6CRU-, Boi1CRU- or Boi $1_{\triangle 86-}$ ${ }_{178} \mathrm{CRU}$-expressing a-strain. Diploid were transferred as independent quadruplets on SD media containing $1 \mathrm{mg} / \mathrm{ml} 5$-FOA, and different concentrations of copper to adjust the expression of the $\mathrm{N}_{\mathrm{ub}}$ fusions (Fig. S1) (Dunkler, Muller, Johnsson 2012). Individual Split-Ub interaction analysis: CRU- and Nub- expressing strains were mated or coexpressed in haploid cells, and spotted onto medium containing $1 \mathrm{mg} / \mathrm{ml}$ FOA and different concentrations of copper in four 10 -fold serial dilutions starting from $O D 600=1$. Growth at $30^{\circ} \mathrm{C}$ was recorded every day for 2 to 5 days.

\section{Microscopy}

Wide-field and confocal microscopy 
Fluorescence microscopy was performed on an Axio Observer Z.1 spinning-disc confocal microscope (Zeiss, Göttingen, Germany) containing a switchable Evolve512 EMCCD (Photometrics, Tucson, USA), or an Axiocam Mrm camera (Zeiss, Göttingen, Germany). The microscope was also equipped with a Plan-Apochromat $100 \times / 1.4$ oil DIC objective, and $488 \mathrm{~nm}, 561 \mathrm{~nm}$, and $635 \mathrm{~nm}$ diode lasers (Zeiss, Göttingen, Germany). Images were recorded with the Zen2 software (Zeiss, Göttingen, Germany), and analyzed with FIJI. Alternatively, time-lapse microscopy was performed with a DeltaVision system (GE Healthcare, Freiburg, Germany) provided with an Olympus IX71 wide field microscope (Olympus, Hamburg, Germany). This microscope contained a CoolSNAP HQ2-ICX285, or a Cascade II 512 EMCCD camera (Photometrics, Tucson, USA), a 100× UPlanSApo $100 \times 1.4$ Oil $\infty / 0.17 /$ FN26.5 objective (Olympus, Münster, Germany), a steady-state heating chamber, and a Photofluor LM-75 halogen lamp (89 NORTH, ChromaTechnology, Williston, USA).

Secretory vesicles in the bud tip were observed with an iMIC microscope (Photonics, Pitsfield, USA) equipped with an Andor-Clara camera (Type Clara DR 328G-C01-SIL CCD), an Oligochrome (Ex 390/40; 482/20; 563/20; 640/20), a LED camera with excitation filters FF01-340/26-25, FF01-387/11-25, and FF01-470/22-25, and a 60xOil Olympus ApoN 60x/1.490oilo/0.13-0.19 objective. The microscope was controlled with the software Live Acquisition (v.2.6.0.34) (FEl Munich, Gräfelfing, Germany). Images were taken in $5 \mathrm{z}$ sections $(\Delta \mathrm{z}=0.5 \mu \mathrm{m})$ with an excitation time of $80 \mathrm{~ms}$ and a laser intensity of $90 \%$.

\section{Structured illumination microscopy (SIM)}

Imaging setup is described in Rüthnick et al. (Rüthnick et al. 2017). Shortly, Alexa488Phalloidin stained cells were suspended in PBS and imaged with a Nikon N-SIM system equipped with total internal reflection fluorescence Apochromat $100 \times 1.49 \mathrm{NA}$ oil immersion objective, and a single photon-detection electron-multiplying charge- 
coupled device camera (iXon3 DU-897E; Andor Technology, Belfast, UK) using a 488 nm Laser for excitation with an emission bandpass filter 520/45. Reconstructions were performed with the image analysis software (Nikon, Tokio, Japan). Images were taken in 5 z sections.

\section{Quantitative analysis of fluorescence microscopy}

All microscopy files were processed and analyzed with FIJI (US National Institute of Health; Version 2.0.0-rc-69) (Schindelin et al. 2012). Images were acquired as 5 to 14 z-stacks and analyzed either in single layers or as projections of single layers.

The number of actin filaments running in parallel to the mother-bud axis within the bud or mother of yeast cells was determined with the assistance of the FIJI tool "Plot profile". Filaments were counted at a position half way in the bud or half way in the mother compartment. Local intensity maxima were considered as actin filament counts. Quantification in the local enrichment of fluorescence intensity ( $R I=$ Relate Intensity) was calculated base on the formula:

$\mathrm{RI}=($ I ROI-IBackground)/(ICytosol- IBackground). IROI describes the mean intensity within the region of interest (ROI), IBackground describes the mean intensity within a region outside of the cell, and ICytosol describes the mean intensity within a region of the cytosol of the mother compartment.

To determine the local enrichment of GFP fusion proteins at peroxisomes, the mean intensity in the GFP channel at all mother cell-located peroxisomes was averaged to determine IROI. The coefficient of variation (COV) used to determine actin cable staining density was calculated as the ratio of standard deviation (s.d.) to the mean fluorescence intensity of the whole mother cell or bud (Garabedian et al. 2018). A less dense actin cable network contains larger dark, cable-free regions. This results in a higher s.d. and a lower mean fluorescence intensity, thus increasing the COV. 
The vesicle distribution in the bud of cells expressing GFP-Sec4 was determined from SIM images with the FIJI tool "Plot profile" by setting a ruler from the bud neck to the bud tip. The relative length was divided into $5 \%$ steps from $0 \%$ at the bud neck to 100 $\%$ at the tip. Along this line (thickness: $0.16 \mu \mathrm{m}=5$ Pixel) the mean fluorescence intensity was determined and the background subtracted. The mean intensities along this line represent relative intensities normalized to the highest mean intensity. 10 cells with bud lengths between 2 and $2.5 \mu \mathrm{m}$ were analyzed for each genotype.

SIM image processing

Images were stacked to maximum projections. Background subtraction for the determination of actin cable numbers and actin cable staining density in bud and mother was performed with the "running ball" method in FIJI with a radius of 20 pixels $(=0.64 \mu \mathrm{m})$. To subtract the background for determination of the vesicle distribution in the bud, the highest intensity value in a vesicle-free cytosolic area of the mother was subtracted from all intensities in the bud.

\section{Actin staining}

Exponentially-grown cells were fixed for $10 \mathrm{~min}$ by adding $3.7 \%$ Formaldehyde to the medium. Cells were resuspended in 3.7\% Formaldehyde (in $100 \mathrm{mM} \mathrm{KH}_{2} \mathrm{PO}_{4}$ ), and incubated for $1 \mathrm{~h}$ before buffer was exchanged to $1 \mu \mathrm{M}$ ethanolamine (in $100 \mathrm{mM}$ $\mathrm{KH}_{2} \mathrm{PO}_{4}$ ) for 10 min. Cells were washed twice with PBS, and incubated with $66 \mathrm{nM}$ Alexa-fluorophore-conjugated phalloidin (Thermo Fisher Scientific, Waltham, MA, USA) for 30 min or over night at $4^{\circ} \mathrm{C}$. Actin patches were removed by addition of $100 \mu \mathrm{M} \mathrm{CK}$ 666 (Merck, Darmstadt, Germany) to the cell medium at $30^{\circ} \mathrm{C}, 10 \mathrm{~min}$ before cells were fixed. Samples that were imaged by SIM were prepared with buffers that were filtrated with a $0.22 \mu \mathrm{m}$ syringe filter (TPP, \#99722, Trasadingen, Switzerland) prior to usage.

\section{Vesicle tethering analysis}


Exponential growing cells were embedded between a coverslip and a custom-made glass slide (Glassbläserei, Uni Ulm) into a 3.8\% agarose gel (containing 1xSD medium). Cells were imaged at room temperature (approx. 22- $26^{\circ} \mathrm{C}$ ). To keep conditions constant among different genotypes, we measured the corresponding cells in a defined order and reversed this order during the repetition. To follow individual vesicles in the bud, images (5 z-stacks, $0.5 \mu \mathrm{m}$ per stack) were taken every second. Each time-lapse series included 4 images that were acquired before and 100 images acquired after bleaching the bud of the cell. Tethering time was determined as the time interval between the arrival of a vesicle at the cortex and the time when it disappears. Only vesicles were taken into account that stayed fixed for more than $4 \mathrm{~s}$ at the cortex and were visible in the middle three layers.

Vesicle distribution in the bud

To quantify the vesicle distribution of incoming vesicles in the bud over the whole time course of 100 images, the middle three layers were stacked to maximum projections. Maximum projections of the consecutive 100 images were further maximum projected into a single image. The mean intensity of a corridor below the plasma membrane of the bud was determined using the "segmented line" tool in FIJI with a line width of 3 pixels $(=0.326 \mu \mathrm{m})$, and normalized to the mean intensity of the whole bud. Both mean intensity values were background-subtracted before calculating the ratio.

\section{Vesicle tracking analysis}

Image Acquisition

Yeast cells expressing GFP-Sec4 from a centromeric plasmid under a methionine adjustable $\mathrm{P}_{M E T 1 T}$ promoter were grown in selective medium lacking methionine. Exponentially grown cells were spun down, and resuspended in selective medium. 3.1 $\mu \mathrm{l}$ of the cell suspension were embedded between a glass microscopy slide and a cover slip. Microscopy was performed at room temperature. Images were taken with a 
confocal microscope over a time course of $35 \mathrm{~s}$ using a single z-stack and acquiring images every $100 \mathrm{~ms}$ (Intensity Laser $488 \mathrm{~nm}=20 \%$; excitation time $=50 \mathrm{~ms}$ ). Before the start of each time lapse, an image of the green and red channel was taken to reconstruct the position of peroxisomes in the trajectory plots for post-analysis. The bud of the cells and vesicle-dense regions (in Pex3-Boi1) in the cortex of the mother were subsequently bleached to increase the signal to noise ratio of single vesicles in the mother and daughter cell.

Vesicle tracking

Time-lapse images were analyzed with the MOSAIC suite plugin for Fiji/lmageJ (Sbalzarini and Koumoutsakos 2005; Schindelin et al. 2012). To observe and follow vesicles over time, we adjusted the following parameters, whereas all other variables were left in default mode: For particle detection: i) Particle radius: $0.133 \mu \mathrm{m}$; ii) Percentile (r): 0.3-1.5 (value was adjusted and vesicle detection was verified in randomly chosen images of the time lapse by using the „preview detected“ function). For particle linking: i) Link range: 5 images; ii) Dynamics: Brownian; iii) Displacement: $1.33 \mu \mathrm{m} / 100 \mathrm{~ms}$.

\section{Directionality analysis}

Directionality analysis based on microscopy coordinate measurements of trajectories was performed in $\mathrm{R}$ statistical package (R Core Team 2013). For each cell, we first fitted a linear function delineating the mother cell and the bud. This function was later used to select trajectories originating from the mother cell for downstream directionality analyses. For each trajectory measured over a time span within a given cell, we calculated two Euclidean distance measurements: (1) distance between two subsequent time points and (2) Absolute Euclidean distance (displacement) from the original position. We then took the ratio of the net displacement to the cumulative distance traveled, with a maximum attainable upper limit value of 1 representing a 
perfectly directional trajectory moving in a straight line. For ease of interpretation, we took the log of this ratio, setting the maximum value to 0 while all variations of movement would fall in the negative range. In the final step, we measured area under the curve $(A \cup C)$ of the calculated ratios along the entire length of the trajectory. To test the statistical significance of the directional movement against a random motion, we generated a null hypothesis distribution using a Monte Carlo simulation. To achieve this, coordinate measurements of each trajectory were first randomized and Euclidean and AUC measurements were calculated by following the steps discussed above. This was iterated 1000 times for each trajectory to finally generate the null distribution. Significance test of the empirical AUC was performed using the formula $p=$ $(r+1) /(N+1)$, where $\mathrm{N}$ is the total number of iterations $(1000), r$ counts the number of events in the simulation model that yielded AUC values greater than the empirical/observed AUC, and $p$ is the calculated p-value (Davison and Hinkley 1997). The decision on whether a given trajectory was moving either towards or away from the bud was made strictly based on its final destination as determined by the linear function delimiting the mother cell and the bud. For final percentage of directional trajectories calculations, we excluded short trajectories with lengths less or equal to 9. Statistical comparisons of directionality measurements among genotypes was performed using the non-parametric Kruskal-Wallis one-way ANOVA followed by Dunn's pairwise posthoc test.

\section{Movement towards peroxisomes}

To quantify the number of vesicles moving towards peroxisomes, we overlaid a plot containing vesicle destinations (generated with $\mathrm{R}$ ) with an image of both fluorescent channels taken right before time-lapse microscopy. Peroxisomes at the mother cortex are mainly immobile, allowing us to combine still images with subsequent time-lapse analysis (Fagarasanu et al., 2006). The directionality plot contained i) the destinations 
of vesicle trajectories that were calculated to move directional but away from the bud (not ending in the bud) and ii) the destination of all trajectories. The latter were required to overlay and correctly fit the proportions of the raw microcopy image with the directionality plot in order to locate the peroxisomes on each plot. We counted the number of trajectories moving away from the bud that co-localized or directly neighbored peroxisomal sites within each cell of a given allele.

\section{Author contribution}

O. Glomb, L. Rieger, Y. Wu, and N. Johnsson designed and analyzed the experiments. D. Rüthnick and O. Glomb performed and analyzed the SIM experiments. Y. Wu, L. Rieger and $\mathrm{O}$. Glomb performed the protein interaction screens and analyses. $\mathrm{O}$. Glomb analyzed vesicular traffic and together with $\mathrm{Y}$. Wu the actin cytoskeleton. O. Glomb investigated the Pex3-Boi1 expressing cells. M. Mulaw wrote the software for vesicle analysis and statistically evaluated together with $\mathrm{O}$. Glomb the tracking experiments. N. Johnsson and $\mathrm{O}$. Glomb designed the study. O. Glomb and N. Johnsson wrote the manuscript.

\section{Acknowledgement}

We thank the Nikon Imaging Facility of Heidelberg for granting access to SIM and its analysis. We thank the Institute for General Physiology at Ulm University for providing introduction and access to the IMIC microscope. We thank Ute Nussbaumer, Steffi Timmermann, and Nicole Schmid for strain construction, and Drs. Judith Müller, Alexander Dünkler and Reinhild Rösler for sharing constructs, advice and strains. The work was funded by grants from the DFG to N.J. (Jo 187/5-2; Jo 187/8-1). The authors declare no conflicts of interest. 


\section{References}

Adamo JE, Moskow JJ, Gladfelter AS, Viterbo D, Lew DJ, Brennwald PJ. 2001. Yeast Cdc42 functions at a late step in exocytosis, specifically during polarized growth of the emerging bud. J Cell Biol 155(4):581-92.

Amberg DC, Zahner JE, Mulholland JW, Pringle JR, Botstein D. 1997. Aip3p/Bud6p, a yeast actin-interacting protein that is involved in morphogenesis and the selection of bipolar budding sites. Mol Biol Cell 8(4):729-53.

Bender L, Lo HS, Lee H, Kokojan V, Peterson V, Bender A. 1996. Associations among $\mathrm{PH}$ and $\mathrm{SH} 3$ domain-containing proteins and rho-type GTPases in yeast. J Cell Biol 133(4):879-94.

Chasserot-Golaz S, Vitale N, Umbrecht-Jenck E, Knight D, Gerke V, Bader MF. 2005. Annexin 2 promotes the formation of lipid microdomains required for calciumregulated exocytosis of dense-core vesicles. Mol Biol Cell 16(3):1108-19.

Davison AC and Hinkley DV. 1997. Bootstrap methods and their application. Cambridge: Cambridge University Press.

Donovan KW and Bretscher A. 2015. Tracking individual secretory vesicles during exocytosis reveals an ordered and regulated process. J Cell Biol 210(2):181-9.

Dunkler A, Muller J, Johnsson N. 2012. Detecting protein-protein interactions with the split-ubiquitin sensor. Methods Mol Biol 786:115-30.

Evangelista M, Blundell K, Longtine MS, Chow CJ, Adames N, Pringle JR, Peter M, Boone C. 1997. Bni1p, a yeast formin linking cdc42p and the actin cytoskeleton during polarized morphogenesis. Science 276(5309):118-22.

Fujimura-Kamada K, Hirai T, Tanaka K. 2012. Essential role of the NH2-terminal region of Cdc24 guanine nucleotide exchange factor in its initial polarized localization in saccharomyces cerevisiae. Eukaryot Cell 11(1):2-15.

Gabel M, Delavoie F, Demais V, Royer C, Bailly Y, Vitale N, Bader MF, ChasserotGolaz S. 2015. Annexin A2-dependent actin bundling promotes secretory granule docking to the plasma membrane and exocytosis. J Cell Biol 210(5):785-800. 
Garabedian MV, Stanishneva-Konovalova T, Lou C, Rands TJ, Pollard LW, Sokolova OS, Goode BL. 2018. Integrated control of formin-mediated actin assembly by a stationary inhibitor and a mobile activator. J Cell Biol 217(10):3512-30.

Gonzalez-Jamett AM, Guerra MJ, Olivares MJ, Haro-Acuna V, Baez-Matus X, Vasquez-Navarrete J, Momboisse F, Martinez-Quiles N, Cardenas AM. 2017. The F-actin binding protein cortactin regulates the dynamics of the exocytotic fusion pore through its SH3 domain. Front Cell Neurosci 11:130.

Graziano BR, Jonasson EM, Pullen JG, Gould CJ, Goode BL. 2013. Ligand-induced activation of a formin-NPF pair leads to collaborative actin nucleation. J Cell Biol 201(4):595-611.

Graziano BR, DuPage AG, Michelot A, Breitsprecher D, Moseley JB, Sagot I, Blanchoin L, Goode BL. 2011. Mechanism and cellular function of Bud6 as an actin nucleation-promoting factor. Mol Biol Cell 22(21):4016-28.

Guo W, Tamanoi F, Novick P. 2001. Spatial regulation of the exocyst complex by Rho1 GTPase. Nat Cell Biol 3(4):353-60.

Guo W, Roth D, Walch-Solimena C, Novick P. 1999. The exocyst is an effector for Sec4p, targeting secretory vesicles to sites of exocytosis. Embo J 18(4):1071-80.

He B, Xi F, Zhang X, Zhang J, Guo W. 2007. Exo70 interacts with phospholipids and mediates the targeting of the exocyst to the plasma membrane. Embo $\mathrm{J}$ 26(18):4053-65.

Hetrick B, Han MS, Helgeson LA, Nolen BJ. 2013. Small molecules CK-666 and CK869 inhibit actin-related protein 2/3 complex by blocking an activating conformational change. Chem Biol 20(5):701-12.

Hruby A, Zapatka M, Heucke S, Rieger L, Wu Y, Nussbaumer U, Timmermann S, Dunkler A, Johnsson N. 2011. A constraint network of interactions: Protein-protein interaction analysis of the yeast type II phosphatase Ptc1p and its adaptor protein Nbp2p. J Cell Sci 124(Pt 1):35-46. 
Hume AN, Wilson MS, Ushakov DS, Ferenczi MA, Seabra MC. 2011. Semi-automated analysis of organelle movement and membrane content: Understanding rab-motor complex transport function. Traffic 12(12):1686-701.

Janke C, Magiera MM, Rathfelder N, Taxis C, Reber S, Maekawa H, Moreno-Borchart A, Doenges G, Schwob E, Schiebel E, et al. 2004. A versatile toolbox for PCRbased tagging of yeast genes: New fluorescent proteins, more markers and promoter substitution cassettes. Yeast 21(11):947-62.

Jin Y, Sultana A, Gandhi P, Franklin E, Hamamoto S, Khan AR, Munson M, Schekman R, Weisman LS. 2011. Myosin V transports secretory vesicles via a rab GTPase cascade and interaction with the exocyst complex. Dev Cell 21(6):1156-70.

Johnsson $\mathrm{N}$ and Varshavsky A. 1994. Split ubiquitin as a sensor of protein interactions in vivo. Proc Natl Acad Sci U S A 91(22):10340-4.

Jose M, Tollis S, Nair D, Mitteau R, Velours C, Massoni-Laporte A, Royou A, Sibarita JB, McCusker D. 2015. A quantitative imaging-based screen reveals the exocyst as a network hub connecting endocytosis and exocytosis. Mol Biol Cell 26(13):2519-34.

Kustermann J, Wu Y, Rieger L, Dedden D, Phan T, Walther P, Dunkler A, Johnsson N. 2017. The cell polarity proteins Boi1p and Boi2p stimulate vesicle fusion at the plasma membrane of yeast cells. J Cell Sci .

Laughery MF, Hunter T, Brown A, Hoopes J, Ostbye T, Shumaker T, Wyrick JJ. 2015. New vectors for simple and streamlined CRISPR-Cas9 genome editing in saccharomyces cerevisiae. Yeast 32(12):711-20.

Lepore DM, Martinez-Nunez L, Munson M. 2018. Exposing the elusive exocyst structure. Trends Biochem Sci 43(9):714-25.

Li F and Higgs HN. 2005. Dissecting requirements for auto-inhibition of actin nucleation by the formin, mDia1. J Biol Chem 280(8):6986-92.

Li F and Higgs HN. 2003. The mouse formin mDia1 is a potent actin nucleation factor regulated by autoinhibition. Curr Biol 13(15):1335-40. 
Li P, Bademosi AT, Luo J, Meunier FA. 2018. Actin remodeling in regulated exocytosis:

Toward a mesoscopic view. Trends Cell Biol 28(9):685-97.

Luo G, Zhang J, Guo W. 2014. The role of Sec3p in secretory vesicle targeting and exocyst complex assembly. Mol Biol Cell 25(23):3813-22.

Manavalan P and Johnson WC,Jr. 1987. Variable selection method improves the prediction of protein secondary structure from circular dichroism spectra. Anal Biochem 167(1):76-85.

Masgrau A, Battola A, Sanmartin T, Pryszcz LP, Gabaldon T, Mendoza M. 2017. Distinct roles of the polarity factors Boi1 and Boi2 in the control of exocytosis and abscission in budding yeast. Mol Biol Cell 28(22):3082-94.

Maucort G, Kasula R, Papadopulos A, Nieminen TA, Rubinsztein-Dunlop H, Meunier FA. 2014. Mapping organelle motion reveals a vesicular conveyor belt spatially replenishing secretory vesicles in stimulated chromaffin cells. PLoS One 9(1):e87242.

Meunier FA and Gutierrez LM. 2016. Captivating new roles of F-actin cortex in exocytosis and bulk endocytosis in neurosecretory cells. Trends Neurosci 39(9):605-13.

Morgera F, Sallah MR, Dubuke ML, Gandhi P, Brewer DN, Carr CM, Munson M. 2012. Regulation of exocytosis by the exocyst subunit Sec6 and the SM protein Sec1. Mol Biol Cell 23(2):337-46.

Moseley JB and Goode BL. 2005. Differential activities and regulation of saccharomyces cerevisiae formin proteins Bni1 and Bnr1 by Bud6. J Biol Chem 280(30):28023-33.

Moseley JB, Sagot I, Manning AL, Xu Y, Eck MJ, Pellman D, Goode BL. 2004. A conserved mechanism for Bni1- and mDia1-induced actin assembly and dual regulation of Bni1 by Bud6 and profilin. Mol Biol Cell 15(2):896-907. 
Nakano K, Toya M, Yoneda A, Asami Y, Yamashita A, Kamasawa N, Osumi M, Yamamoto M. 2011. Pob1 ensures cylindrical cell shape by coupling two distinct rho signaling events during secretory vesicle targeting. Traffic 12(6):726-39.

Norden C, Mendoza M, Dobbelaere J, Kotwaliwale CV, Biggins S, Barral Y. 2006. The NoCut pathway links completion of cytokinesis to spindle midzone function to prevent chromosome breakage. Cell 125(1):85-98.

Porat-Shliom N, Milberg O, Masedunskas A, Weigert R. 2013. Multiple roles for the actin cytoskeleton during regulated exocytosis. Cell Mol Life Sci 70(12):2099-121.

Pruyne DW, Schott DH, Bretscher A. 1998. Tropomyosin-containing actin cables direct the Myo2p-dependent polarized delivery of secretory vesicles in budding yeast. $J$ Cell Biol 143(7):1931-45.

R Core Team. 2013. R: A language and environment for statistical computing.[computer program]. Vienna, Austria: R Foundation for Statistical Computing. .

RÃ̄1/4thnick D, Neuner A, Dietrich F, Kirrmaier D, Engel U, Knop M, Schiebel E. 2017. Characterization of spindle pole body duplication reveals a regulatory role for nuclear pore complexes. J Cell Biol 216(8):2425-42.

Rincon SA, Ye Y, Villar-Tajadura MA, Santos B, Martin SG, Perez P. 2009. Pob1 participates in the $\mathrm{Cdc} 42$ regulation of fission yeast actin cytoskeleton. Mol Biol Cell 20(20):4390-9.

Sbalzarini IF and Koumoutsakos P. 2005. Feature point tracking and trajectory analysis for video imaging in cell biology. J Struct Biol 151(2):182-95.

Schindelin J, Arganda-Carreras I, Frise E, Kaynig V, Longair M, Pietzsch T, Preibisch S, Rueden C, Saalfeld S, Schmid B, et al. 2012. Fiji: An open-source platform for biological-image analysis. Nat Methods 9(7):676-82.

Schneider C, Grois J, Renz C, Gronemeyer T, Johnsson N. 2013. Septin rings act as a template for myosin higher-order structures and inhibit redundant polarity establishment. J Cell Sci 126(Pt 15):3390-400. 
Sheu YJ, Santos B, Fortin N, Costigan C, Snyder M. 1998. Spa2p interacts with cell polarity proteins and signaling components involved in yeast cell morphogenesis. Mol Cell Biol 18(7):4053-69.

Sikorski RS and Hieter P. 1989. A system of shuttle vectors and yeast host strains designed for efficient manipulation of DNA in saccharomyces cerevisiae. Genetics $122(1): 19-27$.

Storici F and Resnick MA. 2006. The delitto perfetto approach to in vivo site-directed mutagenesis and chromosome rearrangements with synthetic oligonucleotides in yeast. Methods Enzymol 409:329-45.

Tcheperegine SE, Gao XD, Bi E. 2005. Regulation of cell polarity by interactions of Msb3 and Msb4 with Cdc42 and polarisome components. Mol Cell Biol 25(19):8567-80.

Tu D, Graziano BR, Park E, Zheng W, Li Y, Goode BL, Eck MJ. 2012. Structure of the formin-interaction domain of the actin nucleation-promoting factor Bud6. Proc Natl Acad Sci U S A 109(50):E3424-33.

Umbrecht-Jenck E, Demais V, Calco V, Bailly Y, Bader MF, Chasserot-Golaz S. 2010. S100A10-mediated translocation of annexin-A2 to SNARE proteins in adrenergic chromaffin cells undergoing exocytosis. Traffic 11(7):958-71.

Wittke S, Lewke N, Muller S, Johnsson N. 1999. Probing the molecular environment of membrane proteins in vivo. Mol Biol Cell 10(8):2519-30.

Yue P, Zhang Y, Mei K, Wang S, Lesigang J, Zhu Y, Dong G, Guo W. 2017. Sec3 promotes the initial binary t-SNARE complex assembly and membrane fusion. Nat Commun 8:14236. 


\section{Figure legends}

\section{Figure1}

Boi1/2 interact with Bud6 and Bni1. (A) Cut-outs of a Split-Ub array of diploid yeast cells containing Bud6CRU (left panels), or Bni1CRU (right panels), and co-expressing different $\mathrm{N}_{\mathrm{ub}}$ fusions. The $\mathrm{N}_{\mathrm{ub}}$ and $\mathrm{CRU}$-expressing cells were independently mated four times, spotted in quadruplets and transferred onto medium containing 5-FOA. Growth of four colonies indicates interaction. $\mathrm{N}_{\mathrm{ub}}$-Boi1, and $\mathrm{N}_{\mathrm{ub}}$-Boi2 are highlighted in red and blue (See Fig. S1 for complete array, and Table S1 for list of interaction partners). (B) $4 \mu \mathrm{l}$ of yeast cultures co-expressing the indicated $\mathrm{N}_{\mathrm{ub}}$ and $\mathrm{C}_{\mathrm{ub}}$ fusion proteins were spotted in 10-fold serial dilutions, starting with an $\mathrm{OD}_{600}=1$, on medium containing 5-FOA. $\mathrm{N}_{\mathrm{ub}}$ fusions to Guk1, or Tdh1 should not interact. Upper lanes show the interactions in otherwise wild type yeast. Lower lanes show interactions in the absences of BOI1 (left panel), BUD6 (middle panel) or BNI1 (right panel). (C) As in (B) but with cells co-expressing Bud6CRU (left lanes) or Bni1CRU (right lanes) and the indicated fragments of Boi1 or Boi2 as $\mathrm{N}_{\mathrm{ub}}$ fusions. (D) As in (B) but with cells coexpressing $\mathrm{N}_{\mathrm{ub}}$-Boi1 or $\mathrm{N}_{\mathrm{ub}}-\mathrm{Bud6}$ and C-terminally truncated fragments of Bni1 as $\mathrm{CRU}$ fusions. (E) As in (B) but with cells co-expressing Boi1CRU together with Bud6 or fragments of Bud6 as $\mathrm{N}_{\mathrm{ub}}$ fusions. $\mathrm{N}_{\mathrm{ub}}$-Kel1 should not interact. (F) Extracts of $E$. coli cells expressing $6 x \mathrm{His}$ fusion of Bud6 ${ }_{1-141}$ (left panel), or Boi1 1-300 (right panel) were incubated with sepharose beads exposing GST, or GST- fusions to fragments of Boi1 (left panel), or Bni1 (right panel). Input and bound fractions were separated by SDSPAGE and analyzed by anti-His antibodies after transfer onto nitrocellulose. Corresponding SDS-PAGE and quantification of the Western-blots are provided in Figure S2A-D. (G) as in (A) but with cells expressing Boi1CRU or Boi $1_{\triangle 86-178} \mathrm{CRU}$. Interactions of $\mathrm{N}_{\mathrm{ub}}$-Bud6 and $\mathrm{N}_{\mathrm{ub}}$-Bem1 are highlighted in red and blue (See Fig S2 for complete arrays). Bud6 does not interact with Boi1 ${ }_{\Delta 86-178 .}(\mathrm{H})$ as in $(\mathrm{B})$ but with cells co- 
expressing Bud6CRU (left panel), or Bni1CRU (right panel) with the indicated $\mathrm{N}_{\mathrm{ub}}$ fusions. Boi $1_{\Delta 86-178}$ still interacts with Bni1. (I) Cartoon summarizing the in vivo and in vitro interaction data. The interaction between Bud6 and Bni1 was extensively studied by others (Graziano et al. 2011; Tu et al. 2012). See results section for details. (J)

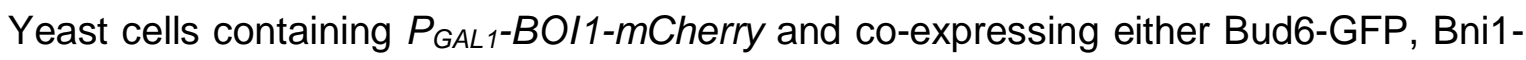
GFP, or Lifeact were shifted to galactose for $4 \mathrm{~h}$ (left panels) and $24 \mathrm{~h}$ (right panels) to induce overexpression of Boi1-mCherry. Shown are the mCherry channel (upper row), the GFP channel (middle row) and the overlay of both channels (lower row). All the GFP fusions are recruit to the cortex upon Boi1 overexpression. Scale bars indicate $2 \mu \mathrm{m}$.

\section{Figure 2}

Mutations in Boi1 influence the actin cytoskeleton. (A) Fluorescence microscopy of $\triangle$ boi2-cells expressing different, genomically integrated fragments of BOI1 under a copper inducible promoter after staining actin with Phalloidin-Alexa488 (left and middle panel), or co-expressing GFP-Sec4 as marker for post-Golgi vesicles (right panel). Scale bar indicates $2 \mu \mathrm{m}$. (B) Quantification of actin phenotypes of cells in (A) according to the categories as shown by the cartoons in the lower panel. Analysis was based on three independent experiments with in total $\mathrm{n}_{B O 11, \Delta \text { boi2 }}=642, \mathrm{n}_{\text {boi1 } \Delta 203, \Delta \text { boiz }}=823$,

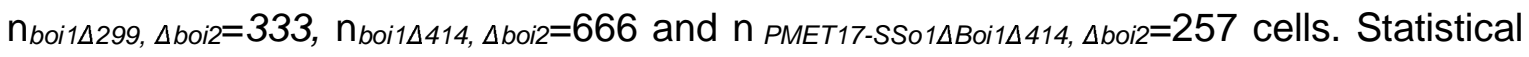
analysis was performed with a two-way ANOVA using a Tukeys-Post-test for multiple comparisons. (C) The ratio of the GFP-Sec4 fluorescence intensities between mother and bud were used to quantify the degree of polarized secretory vesicles in small (s, $<1.5 \mu \mathrm{m})$, medium $(\mathrm{m}, 1.5-3 \mu \mathrm{m})$ and large buds $(\mathrm{l},>3 \mu \mathrm{m})$ of the cells in $(\mathrm{A})$. The experiments were performed in duplicates with two clones analyzed for each genotype

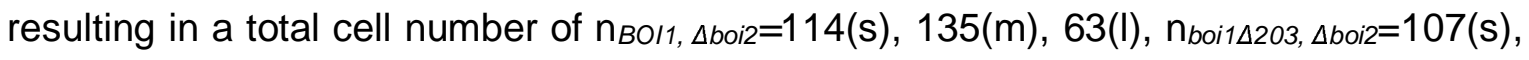




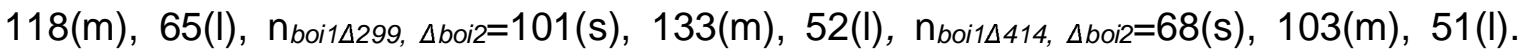
Statistical analysis with calculated $\mathrm{p}$ - values are based on a non-parametric KruskalWallis test followed by Dunn's post test for multiple comparisons. (D) Representative images of cells, treated with $1 \mu \mathrm{M}$ CK-666 for 10 min to dissolve actin patches, were subsequently fixed, stained with Alexa488-Phalloidin, and inspected with SIM. Scale

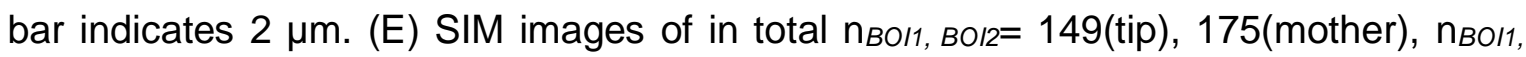

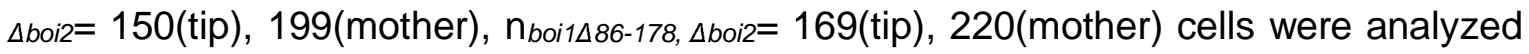
from three independent measurements to quantify the number of actin cables crossing a virtual plane in bud (blue) and mother cell (red) (left, and middle panel). In total $\mathrm{n}_{B O / 1}$,

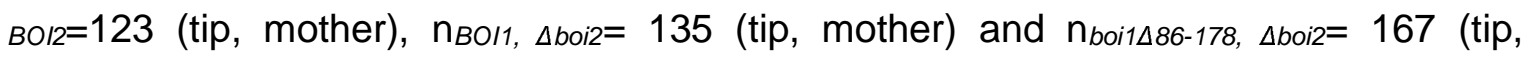
mother) cells were taken to measure the actin cable densities (right panel) ( $\mathrm{COV}=$ coefficient of variation). Statistical analysis was performed with a Kruskal-Wallis test followed by Dunn's post-test for multiple comparisons. All error bars show the s.d of the mean.

\section{Figure 3}

The Boi1-Bud6 interaction is important for vesicle movement and tethering. (A) BOl1 BOI2-, BOI1 $\triangle$ boi2-, and boi1 ${ }_{\Delta 86-178} \Delta$ boi2-cells expressing GFP-Sec4 were analyzed by time-lapse microscopy taking an image of 5 stacks every 1 s over 104 frames. The bud was bleached after 4 frames to visualize incoming vesicles. Upper panel: Projections of the vesicle distribution of the complete time course. Lower panel: Ratios of mean intensities of a corridor below the plasma membrane representing the tethered and docked vesicles to the mean intensity of the entire bud. Error bars indicate the s.d. of the mean ( $n=15$ from two independent experiments for all genotypes tested). Statistical analysis was performed with a Kruskal-Wallis test followed by Dunn's post-test. (B) BOI1 BOI2-, BOI1 $\triangle$ boi2-, and boi1 ${ }_{\triangle 86-178} \Delta$ boi2-cells expressing GFP-Sec4 were fixed 
and visualized by SIM. Upper panel: GFP-Sec4 distributions in cells of the indicated genotypes. Mean intensity profiles of GFP-Sec4 from the bud necks to the tips of 10 cells per genotype (Black: BOI1BOI2, Green:BOI1 $\triangle$ boi2, Blue: boi1 ${ }_{\Delta 86-178} \Delta$ boi2; 5 cells/measurement). Error bars: s.d of the mean. C: Determination of the vesicle tethering time based on time-lapse microscopy from (A). Left panel: Fluorescence microscopy of a wild type cell expressing GFP-Sec4 showing the movement, tethering and fusion of a vesicle in consecutive images. Middle panel: Quantification of vesicle tethering time based on two independent experiments with $\mathrm{n}_{B O 11, B O 12}=102, \mathrm{n}_{B O 11, \Delta \text { boi2 }}=$ 98, $\mathrm{n}_{\text {boi1 } \Delta 86-178, \Delta b o i 2=} 96$ vesicles measured in total. Statistical analysis is based on a Kruskal Wallis test followed by Dunn's post-test. Right panel: Kymograph used for the determination of the tethering time of the vesicle highlighted in the left panel. Scale bar of all images shown indicates $2 \mu \mathrm{m}$.

\section{Figure 4}

A Boi1-Bud6-Bni1 complex initiates actin filaments de novo. (A) Experimental design: Pex3 ${ }_{1-45}$-mCherry was fused to Boi 1 (Pex-Boi1) or to Boi $1_{\Delta 86-178}\left(\right.$ Pex-Boi $\left.1_{\Delta 86-178}\right)$ to target the fusion to the peroxisome allowing to study its actin nucleation activity in isolation from other nucleation factors in the bud. (B) Cells co-expressing the peroxisomal marker Pot1-GFP and Pex-Boi1 were visualized by confocal microscopy. Representative images show maximum projections of $10 \mathrm{z}$ stacks and a clear colocalization of both fusion proteins. (C). Fluorescence microscopy of cells coexpressing Pex-Boi1, or Pex-Boi1 ${ }_{\Delta 86-178}$ together with GFP-labeled Bni1, Bud6, Exo84, or Sec3. Phallodin-Alexa488 staining was used to visualize the actin cytoskeleton of these cells. Scale bars correspond to $2 \mu \mathrm{m}$. (D) Phenotypic quantification of the actin cytoskeleton of cells expressing the indicated color-coded Pex-fusions after Alexa488Phalloidin staining. The categorization into three phenotypes is shown in the cartoons: 
I) Polarized actin cables and patches; II) Mis-localized actin patches, partially colocalizing with peroxisomes; III) Bi-polar actin cable organization with filaments arising from peroxisomes. Data were derived from three independent actin stainings with in total $n_{\text {Pex3-Boi1 }}=553, n_{\text {Pex3-mcs }}=598, n_{\text {Pex3-Boi1 } 186-178}=650$ cells. Bars indicate the mean, and error bars the s.d.. 2-way ANOVA followed by a Tukey's Multiple comparison test were used to determine the significance. (E) Summary of the distributions of different GFP fusions in Pex-Boi1 expressing cells. A quantitative analysis of the distributions is shown in Table S2.

\section{Figure 5}

Pex-Boi1 redirects the flow of post-Golgi vesicles to peroxisomes. (A) Representative images of cells co-expressing GFP-Sec4, or the v-SNARE GFP-Snc1, and either PexBoi1, Pex-Boi1 ${ }_{\Delta 86-178}$, or Pex. Scale bar indicates $2 \mu \mathrm{m}$. (B) Quantification of GFP-Snc1 distributions in cells of $(\mathrm{A})$ (Pex-Boi1 (green), Pex-Boi1 ${ }_{\Delta 86-178}$ (orange), Pex (black)). Distributions were categorized according to the cartoons in the lower panel. The experiments were performed twice with in total $n_{\text {Pex3-Boi1 }}=177, n_{\text {Pex3-mcs }}=107, n_{\text {Pex3- }}$ Boi1 $\Delta 86-178=221$ cells. Statistical analysis was performed with a two-way-ANOVA and Tukeys-multiple comparison post-test. Error bars indicate s.d. of the mean. (C) $\Delta$ boi1 cells co-expressing Pex-mCherry, Pex-Boi1, or Pex-Boi1 ${ }_{\Delta 86-178}$ together with GFP-Sec4 were visualized by confocal microscopy. After bleaching the bud, images were taken every 100 ms over $35 \mathrm{~s}$ to follow the movement of the labeled vesicles. Shown are single cells of each genotype displaying the destinations of all vesicles. Vesicles moving into the bud are labeled orange, vesicles showing directional movement in the mother are painted blue, and the remaining vesicles displaying no, or random movements are in grey. Red arrows indicate the position of the peroxisomes. (D) Quantification of vesicle trajectories of cells shown in $(A)$. Left panel: fraction of 
trajectories of vesicles moving into the bud of cells expressing the indicated Pex3 fusions. Right panel: Number of directional trajectories/cell of vesicles moving towards the peroxisomes displaying the indicated Pex3 fusions. The percentage of vesicles showing directed movement into the bud was calculated in all three alleles shown in (B). Black: $\Delta$ boi1 cells expressing Pex3 ${ }_{1-45}$ mCherry ( $\mathrm{n}=69$ cells); Green: $\Delta$ boi1 cells expressing Pex-Boi1 ( $n=53$ cells); Orange: $\Delta$ boi1 cells expressing Pex-Boi $1_{\Delta 86-178}(n=44$ cells). Data were collected from three independent measurements. Statistical analysis was performed with a Kruskal-Wallis test followed by Dunn's post-test. (E) Directed movements of the vesicles are strictly actin-dependent. Cells co-expressing Pex $3_{1}$ ${ }_{45} \mathrm{mCherry}$ and GFP-Sec4 were treated with $100 \mu \mathrm{M}$ LatA or DMSO (control). Images of a single plane were taken every $100 \mathrm{~ms}$ over $35 \mathrm{~s}$. The percentages of directionally transported vesicles entering the bud were calculated using 24 DMSO-treated, and 22 LatA-treated cells from two independent experiments. Statistical comparison was performed with a Mann-Whitney test. Boxplots in (D) and (E) display the median and 5 to 95 percentile whiskers.

\section{Figure 6}

The Boi-proteins as hubs of polarized secretion and actin filament nucleation. (A) Boi1 binds through its $\mathrm{PH}$ domain to the plasma membrane of the bud and anchors together with phospho-lipids the Bem1-Cdc24 complex to the membrane. Cdc24 activates Cdc42 that is shuttled (red arrows) through Bem1 and Boi1 to its effectors. The Boi1bound Bud6-Bni1 complex initiates and elongates filaments. Those serve as tracks for post-Golgi vesicles to the membrane where they are fixed and kept from spontaneous fusion. In addition Boi1 contacts the exocyst and the SM protein Sec1 to prepare the vesicle for SNARE-mediated fusion (Kustermann et al. 2017). (B) The Boi1/2containing receptor complexes generate the actin filaments that serve as tracks for the 
bioRxiv preprint doi: https://doi.org/10.1101/715409- this version posted July 25, 2019. The copyright holder for this preprint (which was not certified by peer review) is the author/funder, who has granted bioRxiv a license to display the preprint in perpetuity. It is made available under aCC-BY-ND 4.0 International license.

incoming vesicles. Upon fusion, the membrane of the vesicle pushes the receptor complexes apart. The Myo2-driven movement of the next vesicle contracts the receptors to their original position, thus providing directional persistency of the vesicle fusion process. 


\section{Figures}

\section{Figure 1}
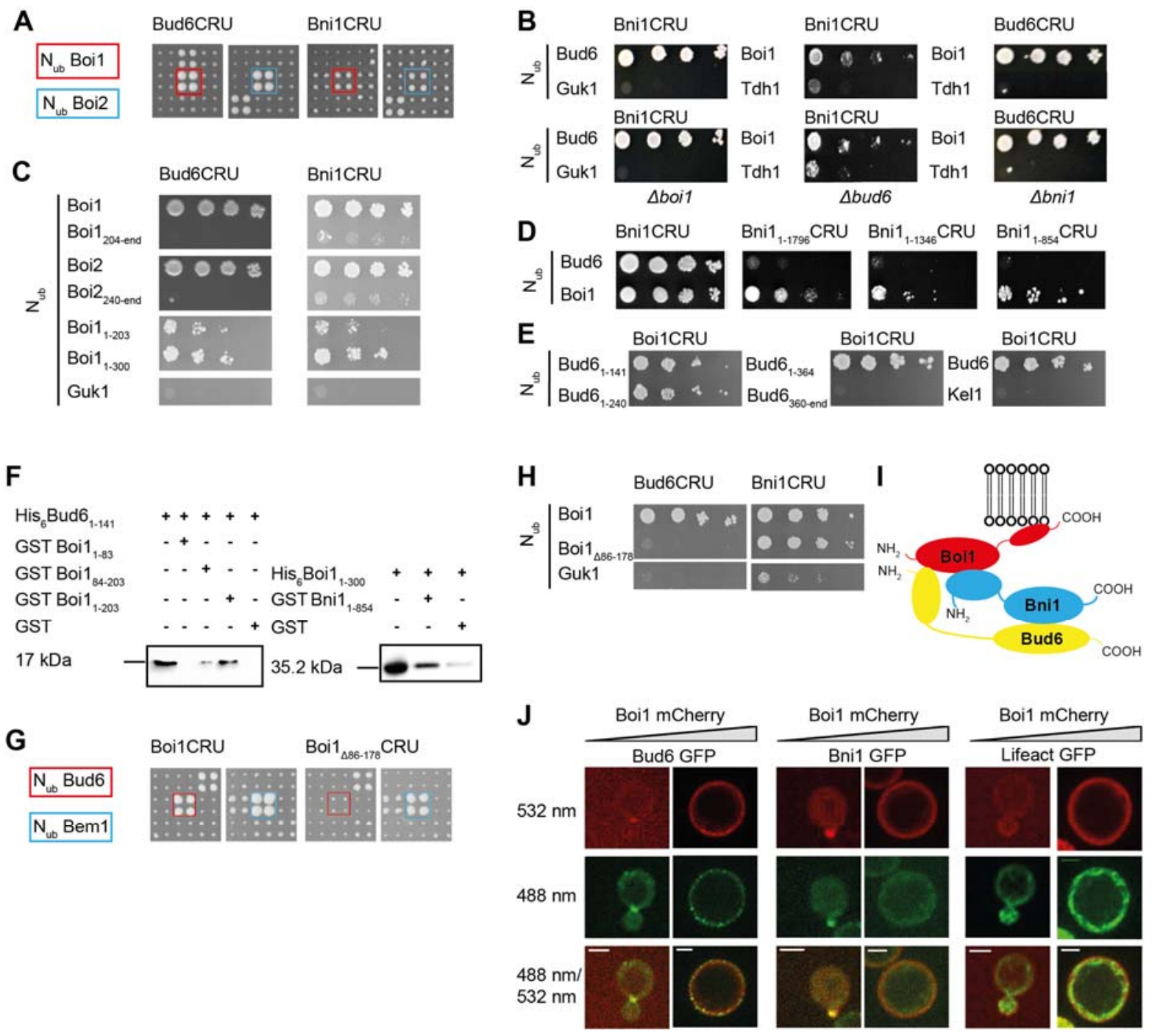


\section{Figure 2}

A

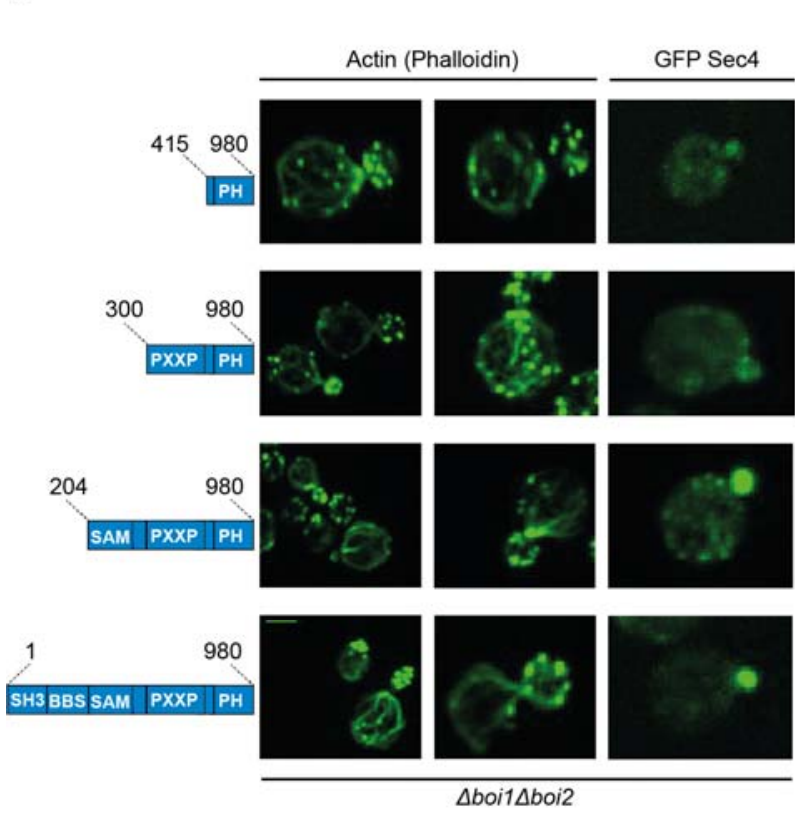

D
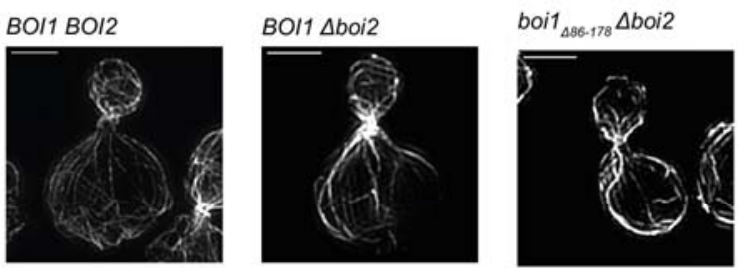

B
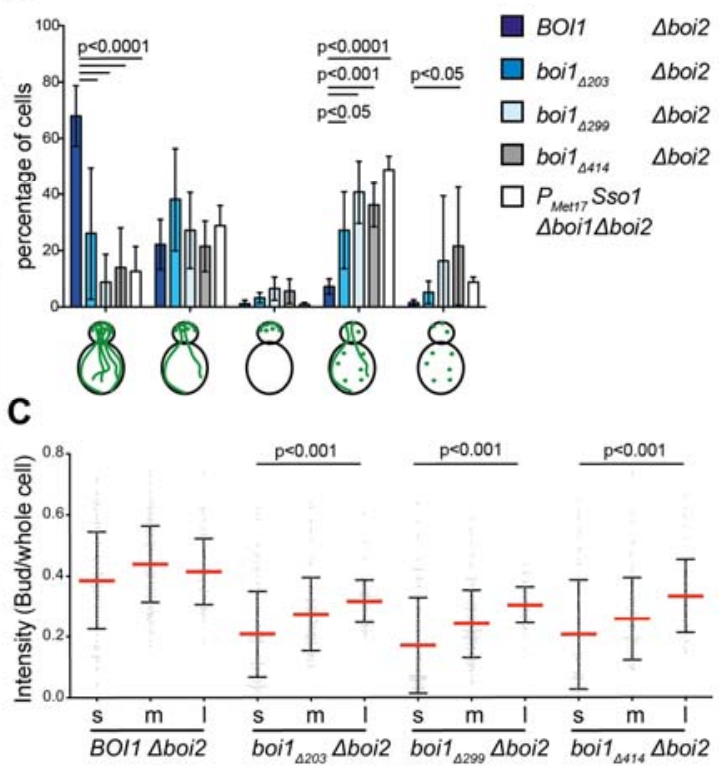

E

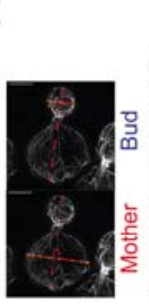

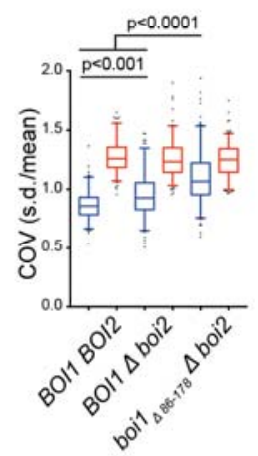

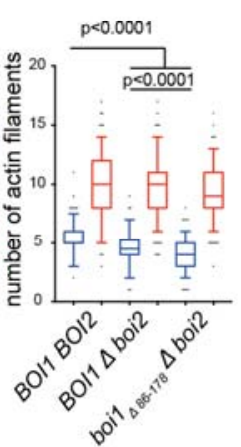




\section{Figure 3}

A

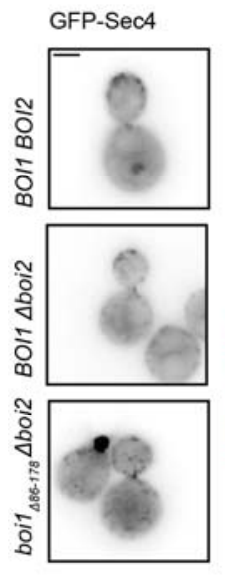

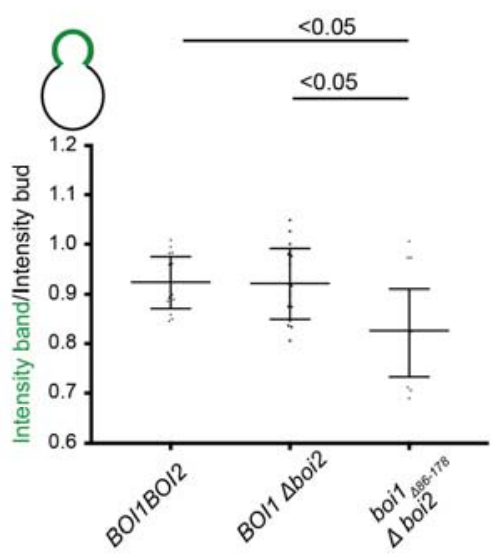

B
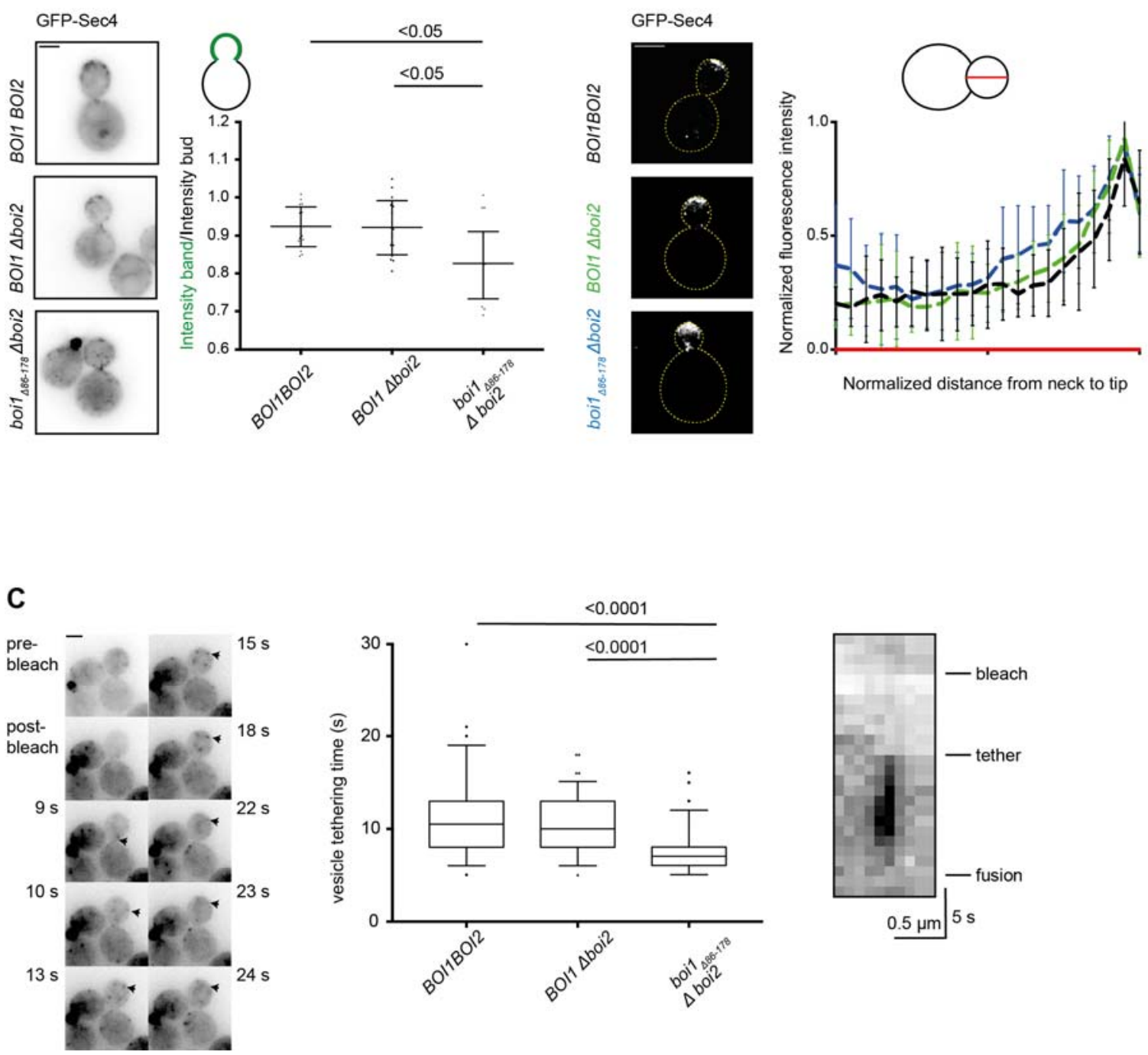
Figure 4

A Rho GTPases

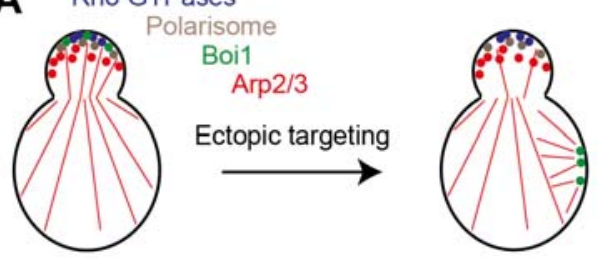

C

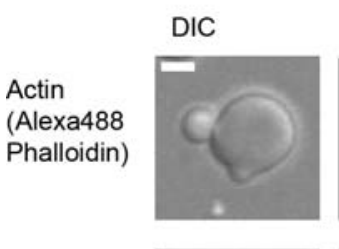

Bni1 GFP
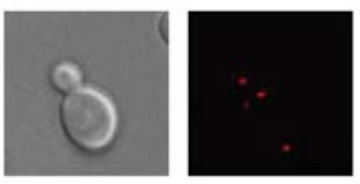

$532 \mathrm{~nm}$

Pex-Boi1

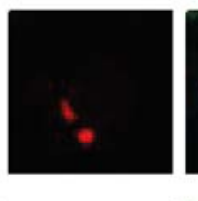

$488 \mathrm{~nm}$

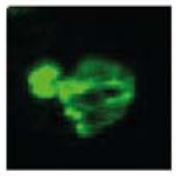

Merge
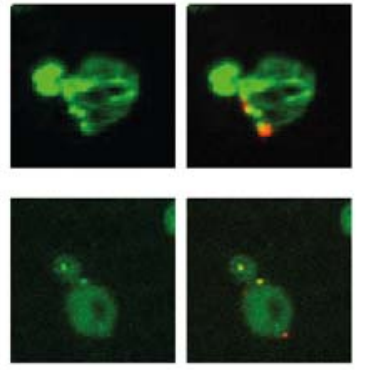

Bud6 GFP
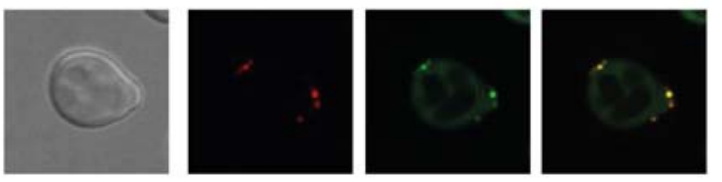

Exo84 GFP
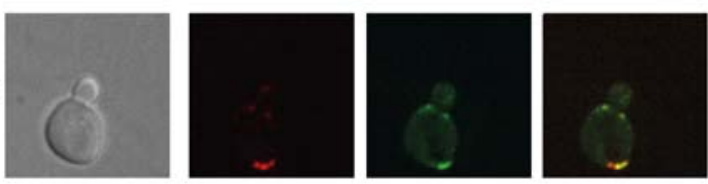

Sec3 GFP
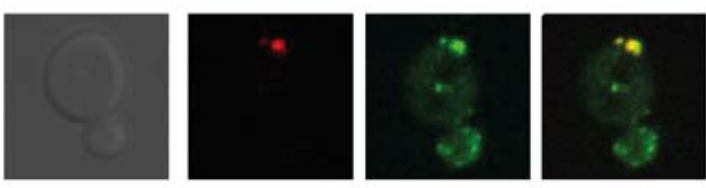

D

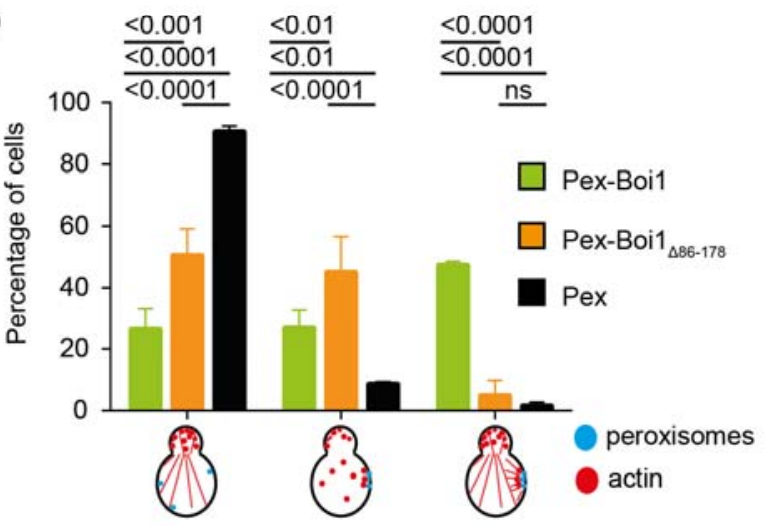

B

Pex-Boi1

Pex
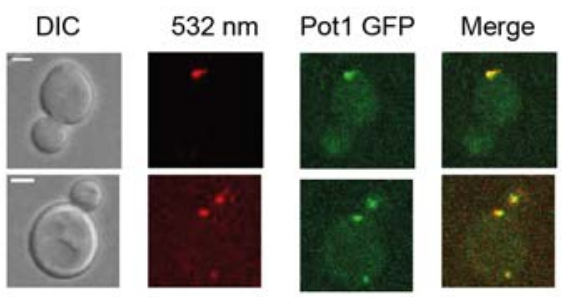

Pex-Boi1 ${ }_{\triangle 86-178}$

DIC

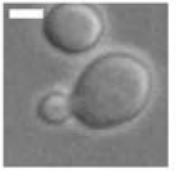

$532 \mathrm{~nm}$
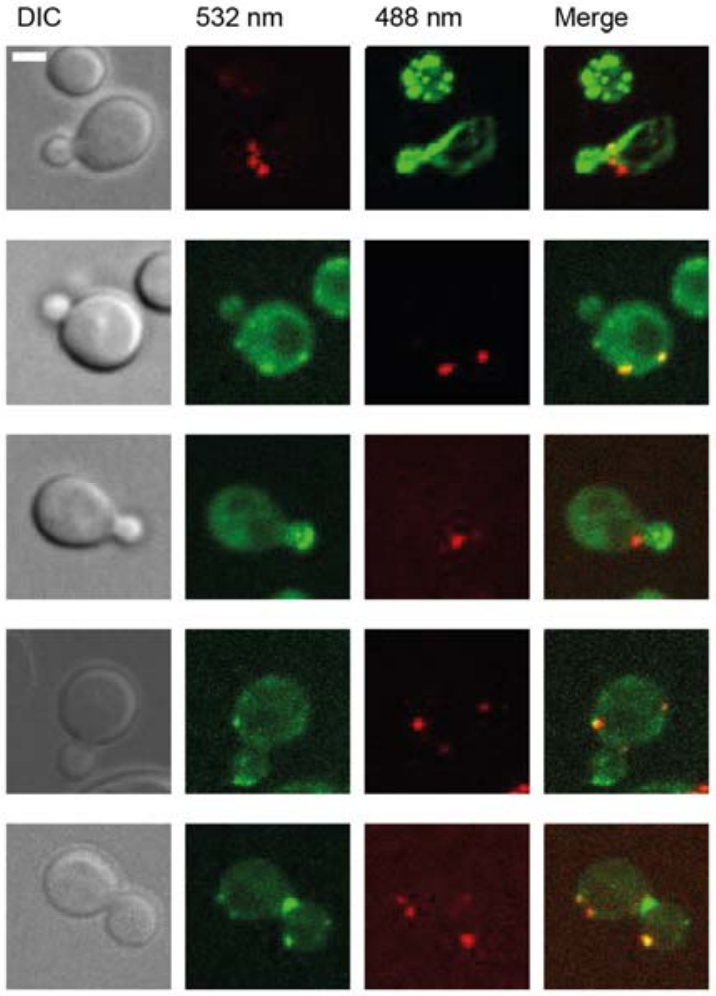

E

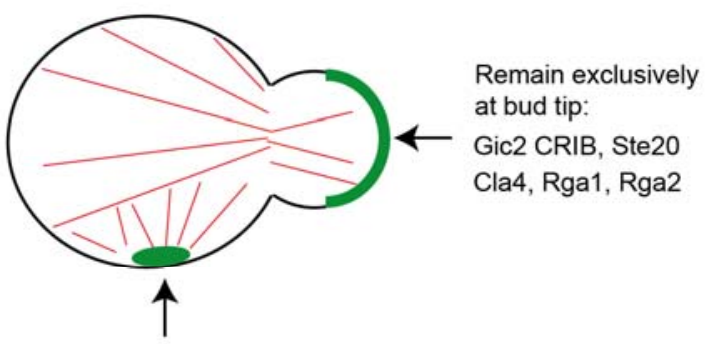

Relocate partially :

Bem1, Cdc24, Cdc42,

Bem2, Bem3

Spa2, Pea2, Bud6, Bni1

Exo84, Sec3, Nba1, Boi2 


\section{Figure 5}

A

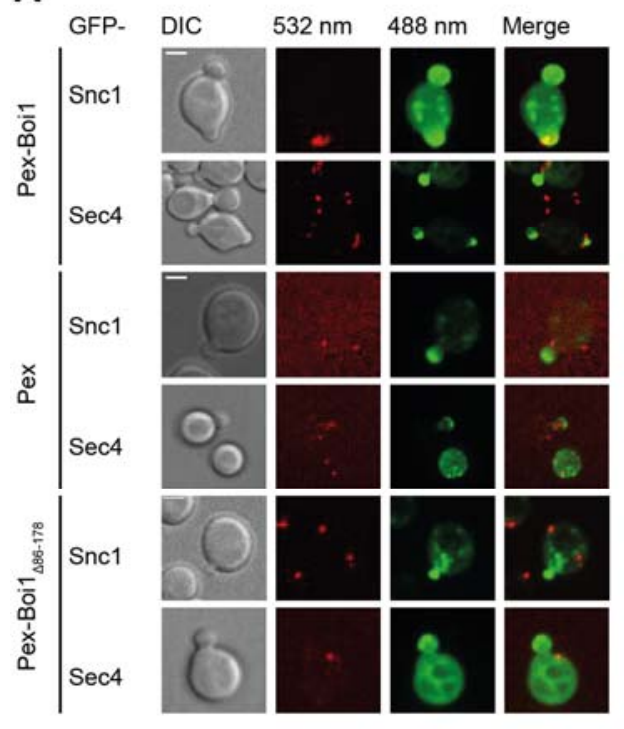

C
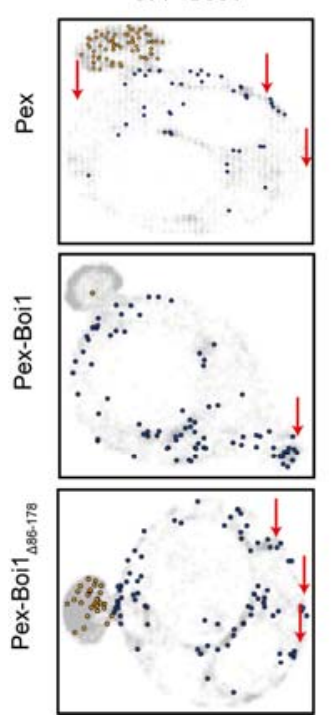

B

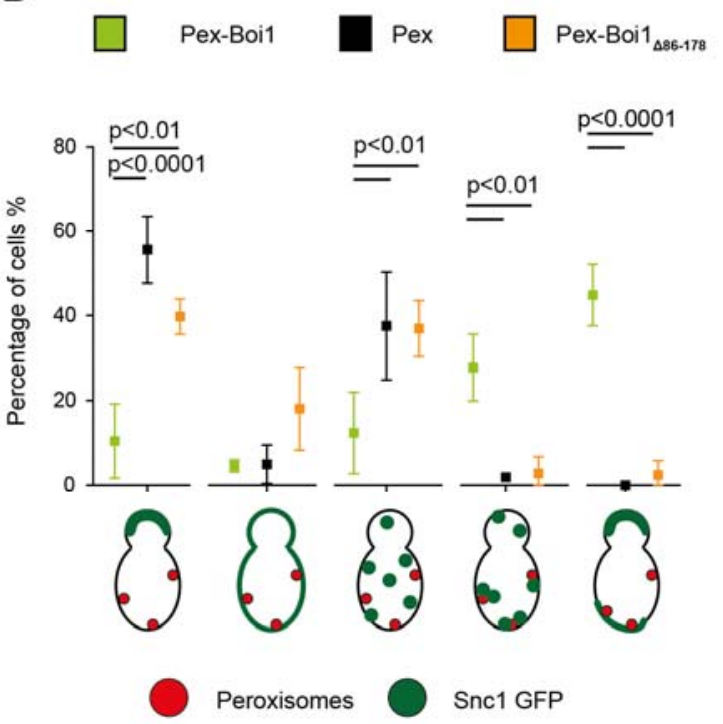

E

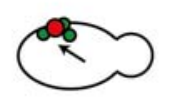

$\mathbf{F}$
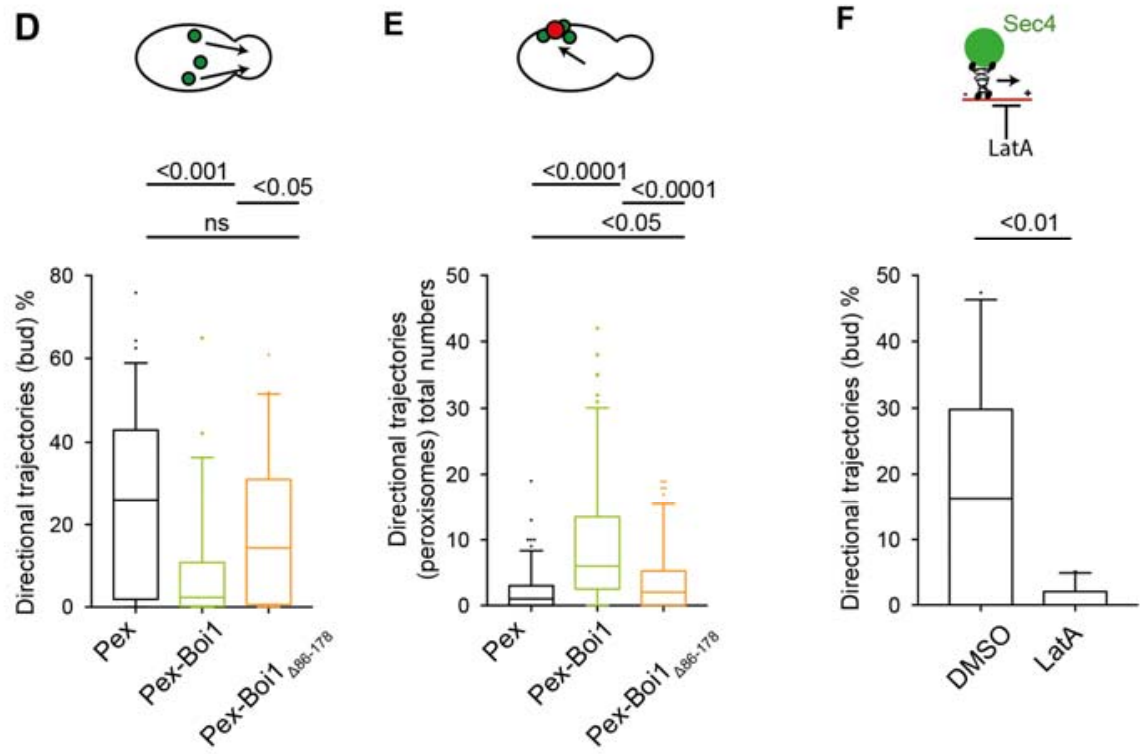
bioRxiv preprint doi: https://doi.org/10.1101/715409; this version posted July 25, 2019. The copyright holder for this preprint (which was not certified by peer review) is the author/funder, who has granted bioRxiv a license to display the preprint in perpetuity. It is made available under aCC-BY-ND 4.0 International license.

\section{Figure 6}

A

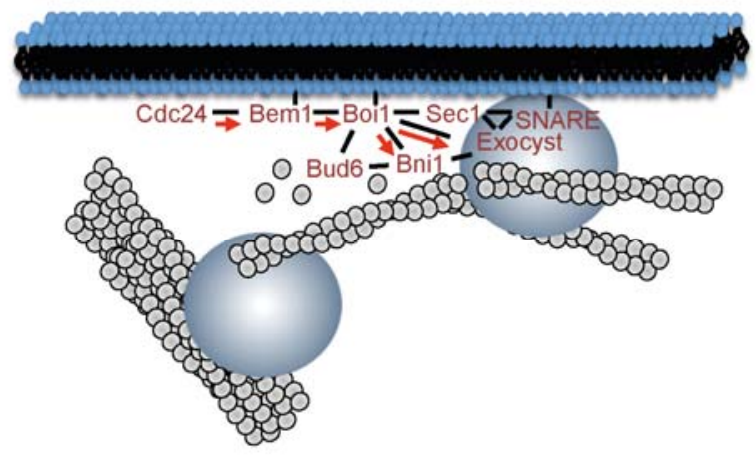

B
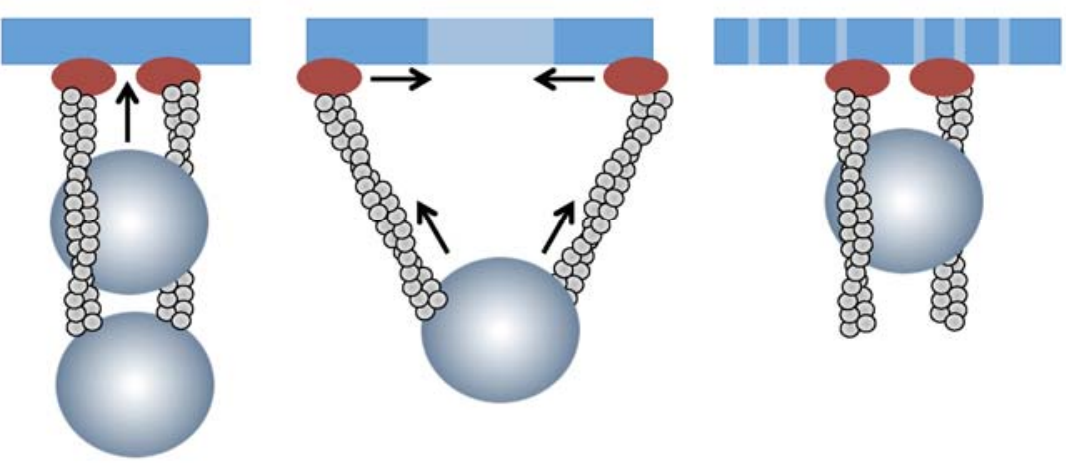